\title{
Application of Immobilized ATP to the Study of NLRP Inflammasomes
}

\author{
Kuo-Chieh Liao ${ }^{1,2, \# \$}$, Christina F. Sandall1,\#, David A. Carlson ${ }^{3}$, Annegret \\ Ulke-Lemée $^{1}$, Jaye M. Platnich² ${ }^{2}$ Philip F. Hughes ${ }^{3}$, Daniel A. Muruve ${ }^{2}$, \\ Timothy A.J. Haystead ${ }^{3}$, and Justin A. MacDonald ${ }^{1, *}$ \\ ${ }^{1}$ Department of Biochemistry \& Molecular Biology, University of Calgary, \\ 3280 Hospital Drive NW, Calgary, AB, T2N 4Z6, Canada \\ ${ }^{2}$ Department of Medicine, University of Calgary, 3280 Hospital Drive NW, \\ Calgary, AB, T2N 4Z6, Canada \\ ${ }^{3}$ Department of Pharmacology \& Cancer Biology, Center for Chemical Biology, Duke \\ University School of Medicine, Box 3813, 450 Research Drive, Durham, NC, 27710, USA \\ \#- Contributed equally to the manuscript \\ \$- Current location: Programme in Emerging Infectious Diseases, Duke-NUS Medical School, \\ Singapore. \\ *To whom correspondence should be addressed: Department of Biochemistry \& Molecular \\ Biology, University of Calgary, 3280 Hospital Drive NW, Calgary, AB, T2N 4Z6, Canada; E- \\ mail: jmacdo@ucalgary.ca; Tel.: 1-403-210-8433
}

Key words: nucleotide-binding oligomerization domain, leucine rich repeat and pyrin domain containing-3, NLRP, inflammasome, fluorescence-linked enzyme chemoproteomic strategy, FLECS, selected reaction monitoring mass spectrometry, SRM-MS, immobilized ATP Sepharose, drug discovery 


\section{ABSTRACT}

The NLRP proteins are a subfamily of the NOD-like receptor (NLR) innate immune sensors that possess an ATP-binding NACHT domain. As the most well studied member, NLRP3 can initiate the assembly process of a multiprotein complex, termed the inflammasome, upon detection of a wide range of microbial products and endogenous danger signals and results in the activation of pro-caspase-1, a cysteine protease that regulates multiple host defense pathways including cytokine maturation. Dysregulated NLRP3 activation contributes to inflammation and the pathogenesis of several chronic diseases, and the ATP-binding properties of NLRPs are thought to be critical for inflammasome activation. In light of this, we examined the utility of immobilized ATP matrices in the study of NLRP inflammasomes. Using NLRP3 as the prototypical member of the family, P-linked ATP Sepharose was determined to be a highly-effective capture agent. In subsequent examinations, P-linked ATP Sepharose was used as an enrichment tool to enable the effective profiling of NLRP3-biomarker signatures with selected reaction monitoring-mass spectrometry (SRM-MS). Finally, ATP Sepharose was used in combination with a fluorescencelinked enzyme chemoproteomic strategy (FLECS) screen to identify potential competitive inhibitors of NLRP3. The identification of a novel benzo[d]imidazol-2-one inhibitor that specifically targets the ATP-binding and hydrolysis properties of the NLRP3 protein implies that ATP Sepharose and FLECS could be applied other NLRPs as well. 
1. The NLRP Inflammasome. The inflammasome is a protein complex and caspase-activating platform that drives inflammation and plays a crucial role in the innate immune response [1-4]. Following stimulation by pathogen or danger/damage associated molecular patterns (PAMPs or DAMPs), inflammasome assembly induces the recruitment and autocatalytic cleavage of procaspases-1, 8 and 11, which are cysteine proteases and the key effectors of the inflammasome [57]. Activated caspases in turn regulate key processes involved in inflammation and host defense that includes cytokine maturation, metabolism, reactive oxygen species (ROS) generation, apoptosis and pyroptosis. For example, pro-IL-1 $\beta$, an endogenous pyrogen that induces fever as well as other immune responses, is cleaved by caspase- 1 into mature IL- $1 \beta$ and is released into the extracellular environment to fulfill its physiological functions [8].

Each inflammasome has scaffold proteins that determine inflammasome specificity and mediate its assembly. The nucleotide-binding oligomerization domain, leucine rich repeat and pyrin domain containing-3 (NLRP3) protein is the most extensively studied inflammasome scaffold protein. This protein belongs to the 14-member NLRP subfamily of the immune sensor Nod-like receptor (NLR) family [9]. NLRP3 possesses an N-terminal pyrin domain (PYD), a central NAIP, CIITA, HET-E and TP1 (NACHT) domain, and a C-terminal leucine rich repeat (LRR) domain [10]. The PYD of NLRP3 has been demonstrated to interact with pro-caspase-1 via an adaptor protein, apoptosis-related speck-like protein (ASC) $[11,12]$. The NACHT domain binds to and hydrolyzes ATP and contributes to NLRP3 inflammasome assembly and activation [13]. Although limited direct evidence has been provided, the LRR domain is thought to be responsible for detecting a wide spectrum of NLRP3 ligands that include nigericin [14], asbestos [15], silica [16], $\beta$-amyloid [17], cholesterol crystals [18], fatty acids [19], urate crystals [20], aluminum oxide [16], along with certain engineered nanomaterials [21] and other implanted metal medical devices 
[22]. Generally, a two-step model has been proposed for canonical NLRP3 activation [23]. First, transcriptional priming of NLRP proteins and cytokine precursor proteins is induced via NF- $\mathrm{KB}$ signaling. The second step is driven by the accumulation of cellular danger signals, such as ROS [15,23], potassium and/or calcium flux [24-26], and/or lysosomal disruption [16,18]. More recently, mitochondria have also been demonstrated to play a critical role in NLRP3 inflammasome assembly [27-31]. In addition, it has been recently reported that RNA binding proteins provide post-transcriptional regulation of NLRP3 [99]. Collectively, NLRP3 activity is controlled multiple levels with important control also existing at the post-translational level via phosphorylation [32-34] and/or ubiquitination [35-37].

2. NLRPs possess ATP-binding Properties. Comparative sequence analyses reveal conservation within NACHT that designate NLRPs as members of the Signal Transduction ATPases with Numerous Domains (STAND) clade within the larger ATPases-Associated with various cellular Activities (AAA+ ATPase) superfamily of proteins [38-40]. The vast majority of STAND ATPases are modular proteins, containing multiple domains involved in DNA or protein binding, signal transduction and scaffolding. STAND proteins have a conserved core, containing enzymatic ATPase activity, as well as key domains involved in sensing of stimuli, and effector domains for downstream signaling. A conserved mechanism of activation has been proposed, based on the structural-function relationships of four different STAND ATPases [41]. Briefly, the integrated data suggest that STAND ATPases function as regulated molecular switches, which undergo structural reorganizations corresponding to monomeric, resting ADP-bound forms in the off position, and ATP-bound, oligomeric forms in the on position, which can signal downstream via protein-protein interactions in the aforementioned effector domains. 
All the different NLRP proteins possess a NACHT domain that is expected to mediate ATPbinding and hydrolysis [9]. A primary sequence alignment of the NACHT domain of each NLRP reveals multiple conserved regions for ATP-binding (e.g., Walker A and Walker B motifs, GxP, motif as well as a Winged-helix domain) [42-44]. Yet, only NLRP3 [13], NLRP7 [45] and NLRP12 [46] have been empirically defined to possess ATP-binding potential and intrinsic ATPase activity. Mutations in the ATP-binding regions (e.g., the Walker A motif) within these specific NLRP proteins abolished their ATP-binding and ATPase activities and thereby resulted in impaired IL-1 $\beta$ maturation $[13,46]$. The biochemical assessments employed to date have been quite rudimentary in nature, and a comprehensive kinetic characterization of the enzymatic nature of any NLRP protein has yet to be completed (i.e., $K_{\mathrm{M}}$ for ATP binding, $\mathrm{V}_{\max }$ for ATP hydrolysis, and turnover number $\mathrm{k}_{\text {cat }}$ ). While it was evident that NLRP1 inflammasome activation was nucleotide dependent [47], the capacity of NLRP1 to hydrolyze ATP is not yet resolved. Although the seminal paper linked the contribution of nucleotide-binding to the functional role of NLRP1[47], a soluble fragment of the protein containing the NACHT domain and the LRR exhibited negligible ability to hydrolyze triphosphate nucleotides [48]. As a whole, the basic enzymology of the NLRPs remains under-characterized, and further description of the role played by the NACHT in driving inflammasome activation and the ensuing inflammatory signaling pathways will be critical for a comprehensive understanding of this family and their role in human disease.

\section{Application of Immobilized ATP Supports to the Study of NLRPs. Many different protein} families possess biochemical properties in terms of amino acid sequence and three-dimensional structural folds that enable ATP-binding. Two major groups of enzymes are associated with 
binding of ATP: the AAA+ ATPases and the universal stress protein (USPs) which bind and hydrolyze ATP, and the kinases which bind and mediate the transfer of the $\gamma$-terminal phosphoryl of ATP to another molecule (i.e., to a small molecule by metabolic kinases such as 6phosphofructokinase or to another protein substrate by protein kinases). Historically, biochemical studies of these proteins were advanced with the application of immobilized ATP solid support resins. These chromatography media are prevalent in the literature for ATP-binding studies and for affinity purification of ATP-binding proteins [49-55]. Indeed, the ATP-binding properties of NLRP3 were demonstrated using an N-linked ATP Sepharose resin [56]. The protein binding efficiency is particularly sensitive to the type of chemistry employed in the ATP linkage. Both the physicochemical properties and length of the linker, as well as its position on the ATP molecule can interfere with binding, thereby reducing capture efficiency. A variety of different resins can be synthesized (Figure 1), and these are typically generated by coupling ATP to the solid support matrices via the available reactive groups present on the ribose sugar (R-linked), the adenine base (N-linked) or the $\gamma$-phosphate (P-linked). Different types and lengths of linker arms (e.g., aminophenyl and alkyl groups spanning up to 10 carbon atom spacers) as well as solid support matrices (i.e., Sepharose, agarose and magnetic beads) can be employed to optimize the most effective protein binding response.

INSERT FIGURE 1 HERE

\subsection{Impact of Orientation and Crosslinking on NLRP3 Capture with Immobilized ATP.} Structural examinations of the NLRP-related APAF1 and NLRC4 folds have established that both proteins adopt closed conformations with the nucleotide buried deeply within the active site $[42$, 
57]. In the nucleotide binding site of APAF1, the $\mathrm{N} 1$ and $\mathrm{N} 6$ atoms of the adenine ring are coordinated by the main-chain amide and carbonyl groups of Val127 [42]. Likewise, hydrogen bonds between ADP and the NACHT domain of NLRC4 originate from coordination of the N1 and N6 atoms in the adenine base [57]. Thus, the hydrogen bond arrangements within the NACHT appear to be adenine specific, and therefore provide a specificity filter to disrupt efficient binding of other nucleotides (e.g., GTP) within the site. Indeed, only adenosine nucleotides were able to competitively elute NLRP3 from N-linked ATP Sepharose [13]. Moreover, studies utilizing a fluorescence polarization assay with NLRP1 revealed that ATP-binding was still permitted with fluorophore addition to the purine; whereas, nucleotide-binding following conjugation of fluorophore to the sugar or $\gamma$-phosphate moieties of ATP was not tolerated [47]. Ultimately, the structural topology of nucleotide bound within the NACHT of the APAF1 and NLRC4 suggest that the chemical nature of the ATP Sepharose capture resin, with modification of linker types, lengths and properties, could significantly impact upon binding affinity and recovery of NLRPs.

\section{INSERT FIGURE 2 HERE}

The effect of the molecular linkage of ATP to the Sepharose bead on NLRP3 protein capture efficiency was examined herein by comparing the binding capacity of five ATP Sepharose matrices under conditions of ligand saturation (Figure 2). The P-linked ATP Sepharose was generated by coupling to Sepharose via the $\gamma$-phosphate group [69]. The N-linked Sepharoses were generated by coupled through the N6- and N8- amino groups of the purine ring of the nucleotide, respectively. The R-linked ATP Sepharose was a mixed-bed of ATP coupled to the hydroxyls at either the $\mathrm{C} 2$ or $\mathrm{C} 3$ position of the ribose ring. Importantly we identify the NLRP3-ligand binding 
efficiency to be particularly sensitive to the ATP linkage. The capture efficiency observed with the P-linked ATP Sepharose was the highest, at $96.1 \pm 2.4 \%$, varying with the binding ratio of cell lysate to Sepharose. The binding efficiency of N6-linked ATP Sepharose was low, at 23.9 $\pm 9.1 \%$, while coupling at the N8 position resulted in an increase in capture efficiency to $47.1 \pm 5.9 \%$. The R-linked ATP Sepharose was the least effective for NLRP3 capture, at $18.4 \pm 7.4 \%$. Each binding experiment was performed by incubating whole cell lysates (HEK293T, stably-expressing NLRP3-GFP) with ATP Sepharose at a volumetric ratio of 1:2 (lysate:matrix). The capture efficiency was not impacted with ratiometric increase to 1:4 (lysate:matrix), indicating that ATP ligand concentrations were always supersaturating. Immunoblotting analysis of NLRP3 captured from transiently-transfected HEK293T cells confirmed that the GFP tag did not interfere with the ability to capture NLRP3 on P-linked ATP-Sepharose (Figure 3A), and endogenous NLRP3 protein could also be captured from THP-1 cells with the affinity resin (Figure 3B). Lastly, a cleavable P-linked ATP Sepharose, whereby the ATP molecule (and bound protein) can be cleaved from Sepharose through the reduction of a diazo bond with sodium dithionite could also prove beneficial for protein capture applications (Figure 2). In this case, NLRP3 binding efficiency to the cleavable diazo-P-linked ATP Sepharose was slightly reduced as compared to the noncleavable P-link, at $82.3 \pm 1.5 \%$, suggesting that the chemical identify of the linker used to secure the ATP molecule to the solid support also impacts on binding efficiency.

\section{INSERT FIGURE 3 HERE}

The ligand density of ATP Sepharose was previously suggested to play a role in the capture efficiency of larger proteins [58]. This was postulated to result from steric hindrance generated by 
higher molecular weight proteins on the beads, occluding the access and binding of proteins to proximate ATP molecules. As the NLRP proteins are quite large, ranging from $75 \mathrm{kDa}$ to $170 \mathrm{kDa}$, we initially hypothesized that lowering the immobilized ligand density might improve the capture efficiency. However, enhanced NLRP3 capture was observed with increased concentration of immobilized ATP (Figure 4A). At the lowest ligand density (0.1 $\mu \mathrm{mol}$ ATP $/ \mathrm{mL}$ Sepharose), less than $20 \%$ of the input NLRP3 was captured; while $\sim 80 \%$ of the NLRP3 input was retained on the column with the highest ligand density $(0.25 \mu \mathrm{mol}$ ATP $/ \mathrm{mL}$ Sepharose). We also observed an increase in the competitive elution potential with free [ATP] as the immobilized ligand density on the Sepharose beads was decreased (Figure 4B \& 4C). Although significantly less NLRP3 could be recovered on the resin, a greater proportion of the captured protein could be competitively eluted at free [ATP] less than $50 \mathrm{mM}$. One potential explanation could be an increased capacity of the free ATP molecule to access the NLRP3 binding pocket at lower immobilization densities. Another could be that reducing the immobilized [ATP] on the beads could attenuate any localized rebinding of NLRP3 protein back to the beads after elution. Surprisingly, the maximal NLRP3 recovery with competitive elution using high free [ATP] (i.e., 200-300 $\mathrm{mM}$ ) was only $\sim 40 \%$ (Figure 4C \& 4D). We attribute this phenomenon to localized rebinding effects whereby the displaced NLRP3 is able to re-engage the immobilized ATP ligand. Alternatively, NLRP3 protein in the ATP-bound state may adopt a conformation that requires additional effectors to permit its release from the immobilized ligand. For example, additional protein interactions (e.g., ASC binding upon inflammasome assembly) may be required to facilitate nucleotide exchange from the NACHT domain in a mechanism analogous to the binary switching of small G-protein cycling between GDP-bound, inactive and GTP-bound, active states. Finally, we are uncertain as to the reason for loss of NLRP3 recovery from low ligand density P-linked ATP Sepharose resins (i.e., 
$<0.15 \mu \mathrm{mol} \mathrm{ATP} / \mathrm{mL}$ Sepharose) with high free [ATP] (Figure 4C \& 4D). We speculate that perhaps protein was lost as aggregates on the column due to NLRP3 oligomerization under these conditions.

INSERT FIGURE 4 HERE

3.2. Application of Immobilized ATP for Proteomic Studies of NLRPs. The integration of NLRPs into prognostic and diagnostic assays has been hampered by the number and complexity of inflammasomes, the scarcity of selective antibodies, and the similarity of the family members. Mass spectrometry (MS) - based targeted proteomics with selected reaction monitoring (SRM) is a powerful method for quantification of many dozens of proteins in a single analytical run [59-61]. SRM-MS relies on the detection of a prototypic peptide derived from the protein 'biomarker'. This peptide can be selectively filtered and quantified against an internal reference standard (e.g. a, stable isotope-labeled synthetic peptide, SIS peptide) to yield absolute protein concentration. SRM-MS has an advantage over antibody-based quantitative methods in that it is only dependent on knowledge of tryptic peptide masses that can be easily derived from the protein sequence.

\section{INSERT TABLE 1 HERE}

The NLRP family has not been previously examined with SRM-MS, so we initially completed a comprehensive in silico assessment of annotated proteomic databases to define candidate peptides for experimental validation $[62,63]$. The proteotypic SRM-MS peptides for the different NLRP members take into account annotated single nucleotide polymorphisms (SNPs) 
and splice variants that ensure independence from genetic variability of samples [64]. Potential post-translational modification sites were also considered in refining the peptide choices. As a pilot study, an SRM-MS survey scan for NLRP3 was constructed using Skyline and transitions were empirically confirmed [65]. An empirical validation of SRM-MS peptide choices was completed using heterologous cellular expression of NLRP3 in HEK293 cells. SRM-MS analyses of HEK293 cell extracts recorded 27 peptides with mass ranges of 6 to 21 amino acids that covered $25 \%$ of the NLRP3 sequence (Table 1). For bioinformatic verification, peptides were checked using the SRM collider program [66]. The observed fragments were also compared to the NIST and GPMDB databases to ensure uniqueness [67]. Based on its high signal-to-noise ratio, the peptide GDILLSSLIR was selected as a reasonable proteotypic candidate peptide for NLRP3. This peptide is adjudged to satisfy the criteria for successful SRM-MS application, including signal-to-noise character, peptide storage stabilities, reproducible chromatography capture and elution, MS/MS confirmation of peptide identity, and transition selections. For quantitative applications, an isotope-labelled internal standard (SIS peptide) can be used as an internal calibrant for the GDILLSSLIR peptide to generate an absolute measure of NLRP3 abundance. For quantitation, specific signals (peak areas) derived from the endogenous unlabeled species can be compared to those from the SIS peptides to calculate concentrations.

\section{INSERT FIGURE 5 HERE}

Crude protein extracts (e.g., cell or tissue extracts as well as body fluids such as urine and blood) can be used for SRM-MS. However, in practice many proteins exist below the level of SRM-MS detection unless enrichment strategies are employed to boost signal for effective 
quantitation. It is disappointing that NLRP proteins have not emerged as useful targets for SRMMS biomarker assays despite great interest in the field. Indeed, we could not reproducibly detect the proteotypic NLRP3 peptide GDILLSSLIR (as well as other tryptic peptides) by SRM-MS in cell extracts of PMA-differentiated THP-1 cells following nigericin stimulation (Figure 5), even though the presence of NLRP3 protein is routinely confirmed under these conditions by western immunoblotting. Although the NLRP inflammasomes are generally under-represented in biomarker surveys due to factors that preclude their facile detection (e.g., low-expression levels and peculiar biophysical characteristics), NLRP3 protein can be identified using untargeted MS approaches [68]. So, we applied P-linked ATP Sepharose as a tool for the examination of NLRP3 protein in crude cellular lysates. In this regard, P-linked ATP Sepharose provided effective capture and enrichment of NLRP3 for SRM-MS reporting (Figure 5). NLRP3 was readily identified from four unique peptides with three to five transitions for each. Peak areas of the highest transition (as determined by Skyline) were used as a readout of relative expression, and peptide intensities below the detection limit were excluded. Signal detection was improved ( 20 -fold $)$ by sample processing with immobilized ATP prior to the SRM-MS analysis. This improvement was achieved through concentration of NLRP3 protein in the whole cell extract as well as a reduction in the background signal generated during the SRM-MS run. The results also suggest that distinct relative intensities for different peptides could be elicited, most likely due to differences in access to tryptic cleavage sites for ATP-bound NLRP3. Again, the results support the potential use of the GDILLSSLIR peptide as a reasonable proteotypic candidate for quantitation of NLRP3 following capture with immobilized ATP supports. 
3.3. Application of immobilized ATP with FLECS in NLRP drug discovery. The P-linked ATP Sepharose matrix has been successfully employed in chemoproteomic applications for the rapid screening of drug candidates (e.g., Fluorescence-linked Enzyme Chemoproteomic Strategy (FLECS)) [69-73]. At the core of the FLECS method is the capture of a fluorescently-tagged target protein with immobilized ATP in the presence of the entire cellular purinome. Selective drug candidates can then be identified by their ability to provide competitive elution of the fluorescently-tagged target. While earlier chemoproteomic technology was originally applied to profile protein kinases $[56,74]$; recent studies reveal that metabolic enzymes and other non-kinase purine-utilizing proteins can also be effectively screened with proteome mining using this ATP Sepharose platform $[70,71,73]$. Herein, we have applied FLECS with P-linked ATP Sepharose as a means to screen for NLRP3-interacting small molecules by exploiting the nucleotide-binding properties of the NACHT domain.

\section{INSERT FIGURE 6 HERE}

As a first step, we examined the capture and elution of various GFP-tagged NLRP family members from P-linked ATP Sepharose using FLECS. Various NLRP-GFP fusion proteins were expressed in HEK293T cells, and crude lysates were combined with P-linked ATP Sepharose without further purification. All of the NLRP proteins profiled could be captured and competitively eluted with ATP (Figure 6A \& 6B, respectively). No change in fluorescence intensity was observed for ATP elutions when cell lysates containing expressed GFP were used as controls (data not shown). A significant portion of NLRP-GFP protein remained bound to the affinity resin even with high super-saturating ATP concentrations. This is primarily a result of a rebinding effect 
wherein competitively inhibited proteins immediately experience a high local concentration of immobilized ATP and rebind to the resin instead of eluting. In some cases, the capture of fluorescence signal from cell lysates with ATP Sepharose during FLECS did not correlate with changes in NLRP protein capture as judged by immunoblotting (Figure 6C). Differences with intrinsic fluorescence due to environmental distinctions between the load and unbound fractions may account for this observation. So, the recovery of NLRP-GFPs from the ATP Sepharose during FLECS was also confirmed by immunoblotting the ATP elution fractions. Ultimately, sufficient amounts of NLRP-GFP proteins (except NLRP2-GFP) were captured and competitively eluted with ATP to enable application of the FLECS method to the NLRP family. Interestingly, the efficiency of NLRP2 elution during FLECS was low and negligible amounts of protein were detected by western blotting. Given that the motifs important for ATP-binding are conserved in the NACHT domain of NLRP2 $[43,44]$, it is unclear what accounted for this distinction in binding character.

The FLECS chemoproteomic strategy was used to identify molecules that act in an ATPcompetitive manner towards fluorescence-linked NLRP3 (Figure 7A). First, NLRP3-GFP protein in HEK293T crude lysates was directly loaded onto P-linked ATP-Sepharose beads without further purification. Charged beads were washed and then distributed into each well of a 96-well filter plate in order to screen a library of 3,379 compounds as a test case. A description of the selection criteria for the constituents of the compound library was provided previously [69]. In brief, the compound library was assembled with attention to commercial availability, structural diversity, similarity to known inhibitors of purine-binding proteins, as well as any identifiable reactive liabilities. After elution, the fluorescence of each sample was determined, and a threshold was set to differentiate "positive hits" from inactive drug candidates. The positive hits were further 
confirmed by immunoblotting for NLRP3-GFP protein. Approximately 120 positive hits (3.5\% hit rate) were observed with FLECS for NLRP3. Those compounds providing a 5-fold increase in fluorescence signal over background during FLECS were classified as a positive hit. This value was chosen since it was reflective of the signal development at the $\mathrm{EC}_{50}$ for ATP elutions. The positive FLECS hits were further confirmed with secondary screening by immunoblotting. This analysis revealed nine lead compounds with positive immunoreactivity to NLRP3-GFP protein in the elutions. Some compounds result in false positive reports since they possess intrinsic fluorescence properties; these molecules were recorded as positive hits during the FLECS screen but were unable to provide positive immunoreactivity on confirmatory analyses. The suitability of FLECS as a method to screen a library of compounds for their ability to displace ATP-bound NLRP3 was confirmed with a calculated $Z^{\prime}$ factor of 0.61 [75]. Furthermore, the robustness of FLECS was reflected by its utility in assessing proteins that are not amenable to traditional highthroughput screening (HTS). In the case of NLRP drug discovery, FLECS provided a means to circumvent issues with recombinant NLRP protein expression and the lack of practical HTS assay for enzymatic activity profiling.

\section{INSERT FIGURE 7 HERE}

NLRP3 inflammasome activation can trigger multiple cellular effects in myeloid cells such as macrophages and dendritic cells, a major one being IL-1 $\beta$ secretion $[5,13,76,77]$. Next, we addressed whether the compounds could affect IL-1 $\beta$ release triggered by NLRP3 inflammasome activation. Differentiated THP-1 cells, a human monocytic cell line, were either left untreated or exposed to extracellular ATP in the absence or presence of the compounds. HS203873, a 
benzo $[d]$ imidazol-2-one compound, was the most effective attenuator of ATP-induced IL-1 $\beta$ secretion, to $\sim 35 \%$ of the vehicle control (Figure 7B). In addition, compound HS206461 showed some inhibitory potential on ATP-induced IL-1 $\beta$ secretion. Moreover, administration of compound HS206364 routinely enhanced IL-1 $\beta$ secretion from THP-1 cells. Elevated levels of IL$1 \beta$ were detected when cells were treated alone with HS206364 or in combination with extracellular ATP as an activator of NLRP3 inflammasomes. Likewise, treatment of THP-1 cells with HS206537 also resulted in augmented IL-1 $\beta$ secretion. The significance of this stimulatory effect is not clear, and we did not pursue additional investigations. Six of the compounds had no obvious effect on NLRP3 inflammasome activity in the cell assay, suggesting they have poor bioavailability.

Based on these results, we pursued further examination of HS203873. Differentiated THP-1 cells were primed with LPS and treated with ATP and increasing [HS203873], then cell supernatants were collected to probe maturation of pro-IL-1 $\beta$ and pro-caspase-1. Increasing concentrations of HS203873 caused greater reductions in IL-1 $\beta$ secretion triggered by extracellular ATP exposure (Figure 7C). The NLRP3 inflammasome also regulates pro-caspase-1 processing, and influences the profile of multiple processed caspase-1 fragments (e.g., p10, p20 and p11CARD) that are secreted into the extracellular environment [100]. HS203873 consistently prevented ATP-triggered NLRP3 activation and pro-caspase-1 maturation (Figure 7D). Taken together, these studies suggest that HS203873 could antagonize NLRP3 inflammasome activation following exposure to a DAMP (i.e., extracellular ATP).

The results of THP-1 cell-based experiments collectively suggest that HS203873 could inhibit pro-caspase-1 cleavage and IL-1 $\beta$ secretion via inhibition of the NLRP3 inflammasome. To directly examine the ability of HS203873 to attenuate NLRP3 inflammasome assembly, we 
reconstituted the NLRP3 inflammasome in HEK293T cells, which are deficient in NLRP inflammasome components, by co-expressing NLRP3-GFP and FLAG-NLRP3 tagged variants. By monitoring the co-incident pull-down of NLRP3-GFP during immunoprecipitation with antiFLAG antibody, we demonstrate the spontaneous assembly of a multimeric NLRP3 complex (Figure 8A). The treatment of HEK293T cells with HS203873 provided concentration dependent attenuation of NLRP3 oligomerization in situ (Figure 8B). HS203873 occupation of the NACHT domain was expected to inhibit the ATP hydrolysis properties of NLRP3, and we performed in vitro ATPase assays using fluorometric detection of ADP. Immunoprecipitated NLRP3-GFP could elicit ATP hydrolysis and ADP production (Figure 8C). Importantly, incubation with HS203873 $(100 \mu \mathrm{M})$ could suppress the ATP hydrolysis potential of NLRP3. The concentration-dependent elution of NLRP3-GFP from P-linked ATP Sepharose (Figure 8D) with HS203873 was also assessed. In this case, increasing amounts of GFP-tagged NLRP3 were eluted as concentrations of HS203873 were elevated. As an alternative to the elution approach, we observed the ability of HS203873 to impede NLRP3-GFP binding with immobilized ATP (Figure 8E). Pre-incubation of the cell lysate with increasing concentrations of HS203873 resulted in attenuated capture of NLRP3 protein with immobilized ATP (i.e., more NLRP3 protein remained in the unbound fraction). Although the results support the direct action of HS203873 on NLRP3-dependent ATP hydrolysis and inflammasome assembly, the possibility remains that other components of the inflammasome pathway are also affected. In this regard, additional experiments will need to address whether the compound has any impact on NF- $\mathrm{BB}$ and the expression of NLRP3 during priming. Moreover, additional structure-activity relationship (SAR) studies will be necessary to increase the selectivity and potency of the HS203873 pharmacophore. Given that the majority of the structural information for NLRP3 has been derived from in silico models, more biochemical 
evidence will be helpful to complete our understanding of how the NACHT domain of NLRP3 interacts with ATP-competitive inhibitors.

\section{INSERT FIGURE 8 HERE}

Over the past several years, many small molecules have been reported to block NLRP3 inflammasome activation (Table 2), yet the mechanism for antagonism by most of these compounds generally appears to be indirect in nature. The cytokine release inhibitory drugs (CRID, diarylsulfonylureas) can prevent IL-1 $\beta$ secretion [78]. The ability of CRID3 to attenuate ATP-induced IL-1 $\beta$ post-translational processing is suggested to occur through its targeting of glutathione S-transferase omega 1-1 [79]. Later studies demonstrated that CRID3 could attenuate ASC-dependent inflammasome assembly and caspase-1 processing by NLRP3 and AIM2, but not by NLRC4 [80]. The inhibitory action of CRID3 is thought to involve glutathione S-transferase omega regulation of the interaction of ASC with NLRP3 and maintenance of the inflammasome complex. Most recently, a diarylsulfonylurea termed MCC950 was reported to possess high potency and specificity for NLRP3-dependent IL-1 $\beta$ production [81]. The precise molecular mechanism of action for MCC950 on the NLRP3 inflammasome has not been ascertained; however, the molecule may interact directly with NLRP3 or block NLRP3 homo- and/or heterooligomerization. Given the heterocyclic nature of MCC950, it is possible that the molecule may occupy the ATP-binding site of the NACHT domain and attenuate the ATPase activity of NLRP3. Luteoloside, a flavonoid, can also attenuate NLRP3-associated caspase-1 processing and IL-1 $\beta$ secretion, and its effect is likely associated with a suppression of intracellular ROS [82]. Andrographolide was demonstrated to inhibit NLRP3 activation in macrophages [83]; however, 
its mechanism of action was determined to be via mitophagy and reversal of mitochondrial membrane potential disruption. In addition, bromoxone inhibits NLRP3 activation in a transcription-independent manner [84]. Glyburide, an ATP-sensitive potassium channel inhibitor, can suppress the NLRP3-dependent maturation of pro-caspase-1 and pro-IL-1 $\beta$ [85]. In addition, a small molecule intermediate in the synthesis of glyburide (i.e., the so called 16673-34-0 compound) was also able to inhibit the formation of the NLRP3 inflammasome [86]. Rather than acting directly on the NLRP3 protein, glyburide and its synthetic precursor likely targets an upstream effector of NLRP3 inflammasome activation (i.e., $\mathrm{K}+$ efflux). The benzo[ $d]$ imidazole Fc11a-2 was shown to attenuate the release of caspase-1 from ASC/NLRP3 complexes in response to ATP-stimulation of LPS-primed THP-1 cells [87]. Bay 11-7082, a known NF-кB inhibitor, was also shown to block NLRP3 inflammasome activation [88]. One potential mechanism for Bay 117082 may be that it inhibits linear ubiquitin complex formation which was recently demonstrated to be essential for NLRP3 activation [89,90]. Moreover, 3,4-methylenedioxy- $\beta$-nitrostyrene was proposed to inhibit NLRP3 by blocking assembly of the inflammasome [91]. Intriguingly, both 3,4-methylenedioxy- $\beta$-nitrostyrene and Bay 11-7082 were shown to inhibit NLRP3 ATPase activity [88,91]. Although the exact role of ATP hydrolysis in inflammasome assembly and activation has not yet been empirically defined, it is possible that these two compounds inhibit the ATPase activity of NLRP3 by occupying the ATP-binding pocket within the NACHT domain. This would be in line with our identification of novel ATP-competitive small molecules that can be applied for the selective inhibition of the NLRP3 inflammasome.

INSERT TABLE 2 HERE 
Our identification of a novel pharmacophore that specifically competes against ATP-binding of the NLRP3 protein implies that the ATP-binding pockets of the other NLRPs could be attractive therapeutic targets as well. A few concerted efforts have been made to identify compounds that specifically target the NLRP3 protein. For example, a library of electrophilic 'warhead' molecules possessing $\alpha, \beta$-unsaturated nitrile- or carbonyl-derived functionalities were produced by Cocco and colleagues [92]. The prototypical compound (Compound 9, with $\alpha, \beta$-unsaturated lactone substructure) could directly inhibit caspase-1 and NLRP3 ATPase activities presumably by the irreversible alkylation of regulatory cysteine residues. Additional tuning of the electrophilic warhead reactivity has yielded compounds that irreversibly target NLRP3 with reduced cytotoxicity (e.g., acrylamide derivatives [93] and INF39 [94]). Moreover, Jiang and colleagues recently identified a compound (i.e., CY-09) that binds directly to the NACHT domain and inhibits ATPase activity with associated attenuation of NLRP3 inflammasome assembly [95]. All of the NLRP proteins possess a NACHT domain that presumably binds to ATP, and the importance of ATP binding/hydrolysis in the function of several NLRPs has been demonstrated. The primary sequence alignment of the NACHT domain of each NLRP not only reveals multiple conserved regions for ATP-binding (e.g., Walker A, Walker B and GxP motifs as well as the winged-helix domain) but also identify several distinct amino acids in the ATP-binding pocket. This sequence heterogeneity is predicted to offer a selectivity filter and support the opportunity for development of specific ATP-competitive compounds for each NLRP protein. As ATP elution curves for other NLRP proteins have been generated (Figure 6B \& 6C), this drug discovery platform could be applied to identify small molecules that target select members of the NLRP family.

\section{Materials and Methods}


Reagents- ATP, phorbol 12-myristate 13-acetate (PMA), glyburide, puromycin and N6-linked ATP-Sepharose were purchased from Sigma Chemical Co (St. Louis, MO). All other chemicals were of reagent grade and were obtained from VWR (Edmonton, AB) or Sigma Chemical Co. Plinked $\gamma$-aminodecyl ATP Sepharose was synthesized at Duke University using published protocols [50,69]. Other immobilized ATP resins (R-linked and N8-linked ATP Sepharose resins) were obtained from Jena Bioscience GmbH (Germany). Bay 11-7082 was from Enzo Life Sciences (Farmingdale, NW). Mouse anti-human NLRP3 (Cryo-2, Adipogen, San Diego, CA), mouse antihuman IL-1 $\beta$ (Cell Signaling, Danvers, MA), rabbit anti-human caspase-1 (sc-622, Santa Cruz, Dallas, TX), mouse anti-FLAG M2 (F1802, Sigma Chemical Co.), and rabbit anti-GFP (sc-8334, Santa Cruz) were used for immunoblotting. Sequencing-grade modified trypsin (\#V5111) was purchased from Promega Corp. (Madison, WI). The lead candidate compounds were purchased from Enamine (HS206461, HS206349, HS203903, HS206327, HS206537, HS206364 and HS203873), LifeChemicals (HS208040) or Peakdale Molecular (HS208456). CNBr-activated Sepharose 4B media, anti-rabbit IgG coupled to horseradish peroxidase, and the Enhanced Chemiluminescence Kit were obtained from GE Healthcare.

Synthesis of cleavable P-linked diazo-ATP Sepharose- (E)-4-((5-(2-((tertbutoxycarbonyl)amino)ethyl)-2-hydroxyphenyl)diazenyl)benzoic acid (30 mg, $78 \mu \mathrm{mol}$; [98]) was dissolved in methylene chloride $(3 \mathrm{~mL})$ and treated with TFA $(1.2 \mathrm{~mL})$. After $1 \mathrm{~h}$, the mixture was concentrated to a glass, then concentrated from ethanol $(6 \mathrm{~mL})$ twice. The amine product was dissolved in DMF $(900 \mu \mathrm{L})$ for addition to the resin. In a $50 \mathrm{~mL}$ column, CNBr-activated Sepharose 4B (3 g) was swelled in $1 \mathrm{mM} \mathrm{HCl}(30 \mathrm{~mL})$ and then washed with $1 \mathrm{mM} \mathrm{HCl}(600$ $\mathrm{mL})$. The resin was washed with coupling buffer $(30 \mathrm{~mL})$ and then slurried with coupling buffer 
(15 mL). The mixture was then treated with the amine described above (450 $\mu \mathrm{L}$ of the 900 total). The mixture was tumbled at room temperature overnight. The resin was then drained (little to no color eluted) and washed with coupling buffer (5 x $\left.15 \mathrm{~mL} ; 0.1 \mathrm{M} \mathrm{NaHCO}_{3}, 0.5 \mathrm{M} \mathrm{NaCl}, \mathrm{pH} 8.3\right)$, diluted with more coupling buffer $(\sim 15 \mathrm{~mL})$ and treated with capping solution $(300 \mu \mathrm{L} ; 1 \mathrm{M}$ ethanolamine) and rotated for $1.5 \mathrm{~h}$. The solution was drained and washed with 4 rounds of $21 \mathrm{ml}$ high buffer (0.1 M AcOH/NaAcOH, 0.5 M NaCl, pH 8) and low buffer (0.1 M AcOH/NaAcOH, $0.5 \mathrm{M} \mathrm{NaCl}, \mathrm{pH}$ 4). The resin was drained then washed with coupling buffer $(3 \times 15 \mathrm{~mL})$, diluted with more coupling buffer ( $15 \mathrm{~mL})$ and treated with EDC (298 mg, $1.55 \mathrm{mmol})$, HOBT (210 mg, $1.55 \mathrm{mmol}$ ) and 1,19-diamino-4,7,10,13,16-pentaoxanonadecane (240 $\mathrm{mg}, 0.78 \mathrm{mmol})$ and rotated at room temperature for $3 \mathrm{~d}$. The solution was drained and washed with 4 rounds of high buffer/low buffer (21 mL ea.). The resin was drained then washed with coupling buffer $(2 \times 15 \mathrm{~mL})$, diluted with more coupling buffer $(\sim 15 \mathrm{~mL})$ and treated with EDC (298 mg, $1.55 \mathrm{mmol})$, Nmethylimidazole $(319 \mathrm{mg}, 3.9 \mathrm{mmol})$ and ATP $(885 \mathrm{mg}, 1.55 \mathrm{mmol})$ and rotated at room temperature overnight. The solution was drained and washed with 4 rounds of high buffer $(21 \mathrm{~mL}$ ea.) and then washed with storage buffer $(3 \times 15 \mathrm{~mL})$ and transferred with storage buffer $(20 \mathrm{~mL}$; $0.1 \mathrm{M} \mathrm{KH}_{2} \mathrm{PO}_{4}, \mathrm{pH} 7.4$ with $200 \mathrm{mg} \mathrm{NaN}_{3} / \mathrm{L}$ ) to a vial and stored in the dark at $4{ }^{\circ} \mathrm{C}$ until use.

Preparation of NLRP-GFP Expression Plasmids- NLRP clones were obtained from various sources: NLRP1 (NM_033004.3, a gift of Dr. Jeremy Mogridge, University of Toronto); NLRP2 (NM_001174081.1, Origene Cat\# RC20201357); NLRP3, (NM_004895.4, Origene Cat\# RG220952); NLRP4 (NM_134444.4, University of Lausanne); NLRP6 (NM_138329.2, Creative Biogene Cat\# CDFG007883); NLRP7 (NM_001127255.1, TransOMIC Technologies Cat\# TCH1003); NLRP8 (NM_176811.2, Origene Cat\# RC218775); NLRP9 (NM_176820.3, Origene 
Cat\# RC213515); NLRP10 (NM_176821.3, Origene Cat\# RC211215); NLRP11 (NM_145007.3, Origene Cat\# RC203852); NLRP12 (NM_144687.3, University of Lausanne); and NLRP14 (NM_176822.3, Origene Cat\# RC215050). NLRP genes were amplified by PCR, and then subcloned with restriction digest into the pAcGFP-N1 vector (ClonTech, Cat\# 632469). In some cases, site-directed mutagenesis was performed in order to revert coding-mutations introduced by PCR in NLRP clones to the wild-type sequence associated with the provided gene accession number.

Cell culture- HEK293T cells (ATCC\# CRL-11268) were cultured in Dulbecco's modified Eagle medium (DMEM) supplemented with 10\% (v/v) fetal bovine serum (FBS) and 1\% (w/v) penicillin-streptomycin. Human myelogenous leukemia THP-1 cells (ATCC\# TIB-202) were maintained at $37{ }^{\circ} \mathrm{C}$ and $5 \% \mathrm{CO}_{2}$ in RPMI 1640 media supplemented with $10 \%$ (v/v) FBS, $1 \%$ (w/v) penicillin-streptomycin, $1 \%(\mathrm{w} / \mathrm{v})$ sodium pyruvate and $50 \mu \mathrm{M} \beta$-mercaptoethanol. THP-1 cells $\left(10^{5}\right.$ per well) were seeded and differentiated with $100 \mathrm{nM}$ phorbol-12-myristate-13-acetate (PMA) in 96-well plate for $16 \mathrm{~h}$ prior to all experiments. Differentiated cells were exposed to lipopolysaccharide (LPS; $1 \mathrm{ng} / \mathrm{mL}$ ) for $3 \mathrm{~h}$ prior to media exchange and treatment with extracellular ATP $(5 \mathrm{mM})$ in the absence or presence of small molecule inhibitors of the NLRP3 inflammasome.

IL-1 $\beta$ ELISA and immunoblot analysis of pro-caspase-1 processing- After treatments, THP-1 cell supernatants were collected for IL-1 $\beta$ measurement using ELISA (BD Bioscience, Cat\# 557966) according to manufacturer's instructions. Assays were performed in triplicate for each independent experiment. For the pro-caspase-1 processing assay, supernatants were mixed with SDS-PAGE 
loading dye and then subjected to immunoblotting using a polyclonal anti-caspase-1 antibody (Santa Cruz, Cat\# sc622) at 1:500 dilution.

Cell transfection and generation of stable cell line expressing NLRP3-GFP- For transient transfections, the various NLRP-GFP plasmids were transfected into HEK293T cells $(\sim 70 \%$ confluent) in a 100-mm petri-dish using $15 \mu \mathrm{L}$ PolyJet transfection reagent (SignaGen Laboratories). In order to generate a stable cell line that expressed NLRP3-GFP, pCMV6-A-puro plasmid (10 $\mu \mathrm{g}$ DNA) encoding NLRP3-GFP was transfected into HEK293T cells in a 100-mm petri-dish using $30 \mu \mathrm{L}$ Lipofectamine 2000 (Invitrogen). Approximately $24 \mathrm{~h}$ after transfection, the DMEM culture media was removed and replaced with DMEM containing $5 \mu \mathrm{g} / \mathrm{mL}$ puromycin (Sigma Chemical Co.) to select cells for stable integration of the NLRP3-GFP expressing plasmid.

Drug candidate screening by FLECS- The P-linked ATP Sepharose chromatography resin was prepared as described previously [69]. Crude lysates of HEK293T cells stably expressing recombinant NLRP3-AcGFP were combined with P-linked ATP Sepharose (1:1 slurry, $>50,000$ fluorescence counts per $50 \mu \mathrm{L}$ of ATP Sepharose slurry) in Lysis Buffer $(0.1 \%$ (v/v) Triton X$100,150 \mathrm{mM} \mathrm{NaCl}, 60 \mathrm{mM} \mathrm{MgCl} 2,25 \mathrm{mM}$ Tris- $\mathrm{HCl} \mathrm{pH} 7.5$ containing $1 \mu \mathrm{M}$ microcystin-LR and Complete protease inhibitor cocktail (EDTA-free, Roche) for $1 \mathrm{~h}$ at $4{ }^{\circ} \mathrm{C}$. The buffer was removed by filtration, and the media was washed with 10 column volumes of high salt wash buffer (HSWB; $50 \mathrm{mM}$ Tris- $\mathrm{HCl} \mathrm{pH}$ 7.5, $1 \mathrm{M} \mathrm{NaCl}, 60 \mathrm{mM} \mathrm{MgCl} 2,1 \mathrm{mM} \mathrm{DTT}$ ) followed by 10 column volumes of low salt wash buffer (LSWB; $50 \mathrm{mM}$ Tris- $\mathrm{HCl} \mathrm{pH}$ 7.5, $150 \mathrm{mM} \mathrm{NaCl}, 60 \mathrm{mM} \mathrm{MgCl} 2,1 \mathrm{mM}$ DTT). LSWB was then added to the resin, and the resulting 1:1 slurry was distributed into a 96well filter plate (50 $\mu \mathrm{L}$ per well). Positive control: ATP solution $(90 \mu \mathrm{L}, 1-400 \mathrm{mM}$ in LSWB with 
$10 \%(\mathrm{v} / \mathrm{v}) \mathrm{DMSO})$ was added to control wells. Drug candidate screen: drug candidate $(90 \mu \mathrm{L}$ in LSWB with $10 \%(\mathrm{v} / \mathrm{v})$ DMSO; final concentration of $580 \mu \mathrm{M})$ was added to the remaining wells. After 10 min of incubation at room temperature, the filtrates were isolated by centrifugation into black 96-well catch plates (Costar 3915). The fluorescence intensity of each well was determined using a plate reader (Perkin-Elmer Victor X2 Multilabel Reader, excitation filter $485 \mathrm{~nm}$, emission filter $535 \mathrm{~nm})$.

NLRP ATP-binding and elution experiments- Approximately $24 \mathrm{~h}$ after transient transfection, HEK293T cell pellets were extracted with $500 \mu \mathrm{L}$ of Lysis Buffer. Aliquots of cell lysates $(50 \mu \mathrm{L})$ were incubated with P-linked ATP-Sepharose $(50 \mu \mathrm{L}$, to give a $1: 1$ slurry $)$ at $4{ }^{\circ} \mathrm{C}$ for $1 \mathrm{~h}$. After incubation, the ATP-Sepharose was washed 3 times with $1 \mathrm{ml} \mathrm{HSWB}$ and then 3 times with $1 \mathrm{~mL}$ LSWB. Various NLRP-GFPs were eluted with increasing ATP or drug candidate solutions from the resin. Eluates were transferred to a black 96-well plate for fluorescence measurement by a plate reader (Molecular Devices SpectraMax M2, excitation filter $485 \mathrm{~nm}$, emission filter $535 \mathrm{~nm}$ ) and/or were subjected to SDS-PAGE and immunblotting with anti-GFP antibody (Molecular Probes, Cat\# A11122) at a 1:1000 dilution or with anti-NLRP3 antibody (Adipogen, Cat\# AG20B0014) at a 1:1000 dilution. In some cases, blocking experiments were used to assess the ability of NRLP inhibitors to disrupt binding with ATP Sepharose. Whole cell HEK293T lysates were pre-incubated with $\operatorname{drug}\left(1 \mathrm{~h}\right.$ at $\left.5^{\circ} \mathrm{C}\right)$ prior to capture of NLRP3 protein with ATP Sepharose (conditions above). After incubation, the binding reactions were passed through $0.45 \mu \mathrm{m}$ centrifugal spin-filters (Millipore) to separate ATP Sepharose beads from the unbound lysate fraction. 
NLRP3 inflammasome oligomerization assay- Full-length NLRP3 was cloned into mammalian expression plasmids encoding either an N-terminal FLAG tag or a C-terminal GFP tag. Coimmunoprecipitation assays were completed where oligomerization (under over-expression conditions in HEK293T cells) could be quantified based on the ability to pull down GFP-tagged NLRP3 using FLAG-tagged NLRP3. The pull down of GFP-tagged NLRP3 with FLAG-tagged NLRP3 in the absence of HS203873 treatment served as the positive control, and the results from the ensuing western blot were expressed as percentages of the positive control via densitometry. Co-immunoprecipitation experiments using cell lysates from untransfected, GFP-transfected, NLRP3-GFP alone or FLAG-NLRP3 alone served as negative controls. Each treatment was conducted in a single $60-\mathrm{mm}$ dish of HEK293T cells transfected with $3 \mathrm{mg}$ of each plasmid using calcium phosphate and incubated for $48 \mathrm{~h}$ post-transfection in the absence or presence of HS203873.

NLRP3 ATPase assay- NLRP3 ATPase activity was determined using the ADP Detection Kit (MAK033, Sigma Aldrich) according to the manufacturer's instructions. NLRP3-GFP was expressed in HEK293T cells and purified by immunoprecipitation against the GFP tag. The ATPase activity was monitored in 96-well microplates with $50 \mu \mathrm{L}$ reactions containing $10 \mu \mathrm{L}$ of NLRP3-GFP immunoprecipitate, 25 mM Tris-HCl, pH 7.5, $150 \mathrm{mM} \mathrm{NaCl,} 10 \mathrm{mM} \mathrm{MgCl}, 0.1$ mM ATP in the absence or presence of HS203873 at $37{ }^{\circ} \mathrm{C}$. Some assays used HEK293T cell lysates with GFP expression as a control.

Immunoblotting- Proteins were resolved by SDS-PAGE and transferred to $0.2 \mu$ m polyvinylidene difluoride (PVDF) membranes with a standard Tris-Glycine transfer buffer containing 10\% (v/v) 
methanol. The membrane was washed with TBST (25 mM Tris- $\mathrm{HCl}, 137 \mathrm{mM} \mathrm{NaCl}, 3 \mathrm{mM} \mathrm{KCl,}$ and $0.05 \%(\mathrm{v} / \mathrm{v})$ Tween-20). Non-specific binding sites were blocked with $5 \%(\mathrm{w} / \mathrm{v})$ nonfat dry milk in TBST. Membranes were washed with TBST and incubated overnight with primary antiASC antibody at a 1:1,000 dilution in $1 \%(\mathrm{w} / \mathrm{v})$ nonfat dry milk in TBST. Membranes were incubated for $1 \mathrm{~h}$ with HRP-conjugated secondary antibody (dilution 1:5,000) and developed with enhanced chemiluminescence (ECL) reagent (GE Healthcare, Mississauga, ON). All western blots were visualized with a LAS4000 Imaging Station (GE Healthcare), ensuring that the representative signal occurred in the linear range.

Sample Preparation for SRM-MS- HEK293T or THP-1 cells were washed with ice-cold PBS, suspended in $50 \mathrm{mM}$ AMBIC and then lysed by repetitive vortexing and sonication. The cell lysate was diluted 5-fold with $50 \mathrm{mM}$ AMBIC and then clarified by centrifugation $(13,000 \mathrm{xg}, 10$ minutes, $5^{\circ} \mathrm{C}$ ). The protein concentration was determined by Bradford assay. Protein was reduced and alkylated by sequential incubation with $5 \mathrm{mM}$ DTT (30 minutes, $50{ }^{\circ} \mathrm{C}$ ) and $15 \mathrm{mM}$ iodoacetamide (30 minutes in the dark, ambient temperature). Proteolytic digests were generated by overnight incubation $\left(37^{\circ} \mathrm{C}\right)$ with trypsin at a ratio of 1:50 (w/w) plus an additional $5 \mathrm{mM} \mathrm{DTT}$. The resulting tryptic peptides were frozen at $-20{ }^{\circ} \mathrm{C}$ until SRM-MS analysis.

SRM-MS Program Design- Tryptic peptides from NLRP3 were selected using the Global Proteome Machine Database (GPMDB), ProteinAtlas or from previously published reports. For bioinformatic verification, peptides were checked using the SRM collider program. The SRM-MS method was constructed using Skyline and transitions were confirmed bioinformatically and technically. Some NLRP3 peptides were selected de novo in Skyline. Sites of post-translational 
modifications were also taken into account in the selection of peptides. For technical verification and method optimization, NLRP3 peptides were synthesized as well as derived from trypsindigested heterologous expressed protein. The final SRM-MS method was scheduled using iRT within Skyline to define retention time windows of four minutes to ensure at least ten data points across a peak and less then 100 concurrent transitions.

HPLC and Mass Spectrometer Instrumentation- Chromatography was completed using a Dionex Ultimate 3000 and Chromeleon Express software package with a trap-column under reverseelution conditions (OPTI-TRAP MacroColumn-Peptide $50 \mu$ l, large capacity, $3 \mathrm{~mm}$ x $12 \mathrm{~mm}$; Optimize Technology, Oregon City, OR). A C18 PepMap precolumn (100 ̊ pore size, $5 \mu \mathrm{m}$ particle size, $5 \mathrm{~mm}$ length, $300 \mu \mathrm{m}$ i.d.; ThermoFisher Scientific) was connected upstream of the separation column. Tryptic peptides were separated on a PepMap300 C18 column (5 $\mu \mathrm{m}$ particle size, $300 \AA$ A pore size, $1 \mathrm{~mm}$ x $150 \mathrm{~mm}$, ThermoFisher Scientific) with a 44-minute gradient from $2 \%$ to $40 \%$ acetonitrile with $0.1 \%(\mathrm{v} / \mathrm{v})$ formic acid at a flow rate of $50 \mu \mathrm{L} / \mathrm{min}$. Eluted peptides were subjected to in-line electrospray ionization and analyzed with a hybrid triple quadrupole-ion trap mass spectrometer (QTrap4500 running Analyst software; ABSciex, Framingham, MA).

\section{ACKNOWLEDGEMENTS}

This work was supported by grants-in-aid from the University of Calgary University Research Grants Committee, the Canadian National Transplant Research Program (CNTRP), the Canadian Institutes of Health Research (CIHR) Health Challenges in Chronic Disease Signature Initiative 
(\#THC-13523), and the Canada Foundation for Innovation. K.-C.L. was supported by a University of Calgary Eyes-High Fellowship. C.F.S. was supported by a Natural Sciences and Engineering Research Council (NSERC) Postgraduate Scholarship. D.A.M. was an Alberta Innovates Health Solutions (AIHS) Clinical Senior Scholar and held a Canada Research Chair in Inflammation and Kidney Disease. J.A.M. was an AIHS Senior Scholar and held a Marie Curie International Incoming Fellowship. 
Table 1. SRM-MS screen of NLRP3 for proteotypic peptides. Human NLRP3 protein (UniProtKB: Q96P20) was expressed in HEK293T cells (ATCC: CRP-1573). Whole cell lysates were subjected to tryptic digestion and SRM-MS analyses. The relative SRM-MS signal intensities of tryptic peptides are indicated with: $(+)$ - robust signal and meets limit-of-detection criteria; (?) - identification was unclear based on weak signal intensity of transitions, (-) - not detected, and (n/a) - not examined, outside of dynamic range of mass spectrometer. 


\begin{tabular}{|c|c|c|}
\hline NLRP3 Tryptic Peptides & Residue No. & HEK293 \\
\hline K.MHLEDYPPQK.G & {$[26,35]$} & ? \\
\hline K.GCIPLPR.G & {$[36,42]$} & + \\
\hline K.ADHVDLATLMIDFNGEEK.A & {$[48,65]$} & - \\
\hline K.AWAMAVWIFAAINR.R & {$[66,79]$} & $?$ \\
\hline K.WGSDNAR.V & {$[93,99]$} & - \\
\hline $\begin{array}{l}\text { R.VSNPTVICQEDSIEEEWMGLLEYLSR.I } \\
\end{array}$ & {$[100,125]$} & $\mathrm{n} / \mathrm{a}$ \\
\hline R.FQCIEDR.N & {$[147,153]$} & + \\
\hline R.LGESVSLNK.R & {$[157,165]$} & $?$ \\
\hline R.EQELLAIGK.T & {$[183,191]$} & + \\
\hline K.TCESPVSPIK.M & {$[194,203]$} & + \\
\hline K.MELLFDPDDEHSEPVHTVVFQGAAGIGK.T & {$[204,231]$} & $\mathrm{n} / \mathrm{a}$ \\
\hline K.MMLDWASGTLYQDR.F & {$[238,251]$} & + \\
\hline R.FDYLFYIHCR.E & {$[252,261]$} & + \\
\hline R.EVSLVTQR.S & {$[262,269]$} & + \\
\hline R.SLGDLIMSCCPDPNPPIHK.I & {$[270,288]$} & - \\
\hline $\begin{array}{l}\text { R.ILFLMDGFDELQGAFDEHIGPLCTDWQK.A } \\
\end{array}$ & {$[296,323]$} & $\mathrm{n} / \mathrm{a}$ \\
\hline R.GDILLSSLIR.K & {$[327,336]$} & + \\
\hline $\begin{array}{l}\text { K.LLPEASLLITTRPVALEK.L } \\
\end{array}$ & {$[339,356]$} & + \\
\hline K.LQHLLDHPR.H & {$[357,365]$} & $?$ \\
\hline R.HVEILGFSEAK.R & {$[366,376]$} & + \\
\hline K.YFSDEAQAR.A & {$[384,392]$} & + \\
\hline R.AAFSLIQENEVLFTMCFIPLVCWIVCTGLK.Q & {$[393,422]$} & $\mathrm{n} / \mathrm{a}$ \\
\hline K.QQMESGK.S & {$[423,429]$} & - \\
\hline K.SLAQTSK.T & {$[430,436]$} & ? \\
\hline K.TTTAVYVFFLSSLLQPR.G & {$[437,453]$} & - \\
\hline R.GGSQEHGLCAHLWGLCSLAADGIWNQK.I & {$[454,480]$} & $\mathrm{n} / \mathrm{a}$ \\
\hline K.ILFEESDLR.N & {$[481,489]$} & + \\
\hline R.NHGLQK.A & {$[490,495]$} & + \\
\hline K.ADVSAFLR.M & {$[496,503]$} & + \\
\hline R.MNLFQK.E & {$[504,509]$} & + \\
\hline K.EVDCEK.F & {$[510,515]$} & - \\
\hline K.FYSFIHMTFQEFFAAMYYLLEEEK.E & {$[516,539]$} & $\mathrm{n} / \mathrm{a}$ \\
\hline $\begin{array}{r}\text { R.TNVPGSR.L } \\
\end{array}$ & {$[543,549]$} & - \\
\hline R.DVTVLLENYGK.F & {$[556,566]$} & + \\
\hline K.GYLIFVVR.F & {$[570,577]$} & + \\
\hline R.FLFGLVNQER.T & {$[578,587]$} & + \\
\hline R.TSYLEK.K & {$[588,593]$} & + \\
\hline K.ISQQIR.L & {$[599,604]$} & - \\
\hline K.LQIQPSQLELFYCLYEMQEEDFVQR.A & {$[620,644]$} & $\mathrm{n} / \mathrm{a}$ \\
\hline R.AMDYFPK.I & {$[645,651]$} & + \\
\hline K.IEINLSTR.M & {$[652,659]$} & + \\
\hline R.MDHMVSSFCIENCHR.V & {$[660,674]$} & - \\
\hline R.VESLSLGFLHNMPK.E & {$[675,688]$} & ? \\
\hline R.HLDMVQCVLPSSSHAACSHGLVNSHLTSSFCR.G & {$[699,730]$} & $\mathrm{n} / \mathrm{a}$ \\
\hline R.GLFSVLSTSQSLTELDLSDNSLGDPGMR.V & {$[731,758]$} & $\mathrm{n} / \mathrm{a}$ \\
\hline $\begin{array}{l}\text { R.VLCETLQHPGCNIR.R } \\
\end{array}$ & {$[759,772]$} & ? \\
\hline R.CGLSHECCFDISLVLSSNQK.L & {$[779,798]$} & - \\
\hline K.LVELDLSDNALGDFGIR.L & {$[799,815]$} & + \\
\hline R.LLCVGLK.H & {$[816,822]$} & $(+)$ \\
\hline K.HLLCNLK.K & {$[823,829]$} & $(+)$ \\
\hline $\begin{array}{l}\text { K.LWLVSCCLTSACCQDLASVLSTSHSLTR.L } \\
\end{array}$ & {$[831,858]$} & $\mathrm{n} / \mathrm{a}$ \\
\hline R.LYVGENALGDSGVAILCEK.A & {$[859,877]$} & + \\
\hline K.NPQCNLQK.L & {$[880,887]$} & - \\
\hline R.GNTLGDK.G & {$[920,926]$} & - \\
\hline K.LLCEGLLHPDCK.L & {$[930,941]$} & - \\
\hline K.LQVLELDNCNLTSHCCWDLSTLLTSSQSLR.K & {$[942,971]$} & $\mathrm{n} / \mathrm{a}$ \\
\hline K.LSLGNNDLGDLGVMMFCEVLK.Q & {$[973,993]$} & + \\
\hline K.QQSCLLQNLGLSEMYFNYETK.S & {$[994,1014]$} & + \\
\hline K.SALETLQEEKPELTVVFEPSW.- & {$[1015,1035]$} & - \\
\hline
\end{tabular}


Table 2. Anti-inflammatory compounds associated with inhibition of the NLRP3 inflammasome.

\begin{tabular}{|c|c|c|}
\hline Drug & Target & $\begin{array}{c}\text { Effective } \\
\text { Concentration }\end{array}$ \\
\hline Andrographolide & Undefined & $30 \mu \mathrm{M}[83]$ \\
\hline$\alpha, \beta$-unsaturated carbonyl warheads & NLRP3 & $10 \mu \mathrm{M}[92,93]$ \\
\hline Bay-11-7082 & $\begin{array}{c}\text { NLRP3 } \\
\text { Undefined } \\
\text { TLR - NF- } \beta \beta\end{array}$ & $\begin{array}{c}<15 \mu \mathrm{M}[88] \\
10 \mu \mathrm{M}[90] \\
30 \mu \mathrm{M}[84]\end{array}$ \\
\hline Bromoxone & Undefined & $1 \mu \mathrm{M}[84]$ \\
\hline $\mathrm{C} 172$ & Undefined (NLRP3?) & $<10 \mu \mathrm{M}$ [95] \\
\hline CRID3 & $\mathrm{ASC}$ & $25-50 \mu \mathrm{M}[80]$ \\
\hline CY-09 & NLRP3 & $<10 \mu \mathrm{M}[95]$ \\
\hline Fc11a-2 & $\begin{array}{c}\text { Caspase- } 1 \\
\text { ASC } \\
\end{array}$ & $10 \mu \mathrm{M}[87]$ \\
\hline Glyburide & Undefined ( $\mathrm{K}^{+}$efflux $)$ & $50-100 \mu \mathrm{M}[85]$ \\
\hline INF39 & NLRP3 & $10-100 \mu \mathrm{M}[94]$ \\
\hline Isoliquiritigenin & NLRP3 & $<10 \mu \mathrm{M}[96]$ \\
\hline Luteoloside & Undefined & $25-50 \mu \mathrm{M}[97]$ \\
\hline MCC950 & NLRP3 & $0.1 \mu \mathrm{M}[81]$ \\
\hline 3,4-methylenedioxy- $\beta$-nitrostyrene & NLRP3 & $<5 \mu \mathrm{M}[91]$ \\
\hline 5Z-7-oxozeaenol & TLR - NF- $\kappa \beta$ & $1 \mu \mathrm{M}[84]$ \\
\hline Parthenolide & $\begin{array}{c}\text { Caspase-1 } \\
\text { NLRP3 }\end{array}$ & $10 \mu \mathrm{M}[88]$ \\
\hline Prostaglandin 15d-PGJ2 & Undefined & $20 \mu \mathrm{M}[97]$ \\
\hline Sanguinarine & TLR - NF- $\kappa \beta$ & $5 \mu \mathrm{M}[84]$ \\
\hline TAK-242 (Resatorvid) & TLR - NF- $\kappa \beta$ & $20 \mu \mathrm{M}[84]$ \\
\hline $16673-34-0$ & Undefined & $400 \mu \mathrm{M}[86]$ \\
\hline
\end{tabular}


FIGURE 1. Immobilized ATP for affinity capture applications. Various immobilized ATP Sepharose matrices can be generated by chemical coupling through: the $\gamma$-phosphate group $(\mathrm{P}-$ link), the N6- and N8- amino groups of the purine ring of the nucleotide, respectively (N-link) or either of the hydroxyls at the $\mathrm{C} 2$ or $\mathrm{C} 3$ position of the ribose ring (R-link).

FIGURE 2. Comparison of NLRP3 capture with various ATP Sepharose linkages. Various ATP Sepharose resins were incubated with whole cell lysates obtained from HEK293T cells stably-expressing NLRP3-GFP. ATP Sepharoses included: (A) P-linked (0.25 $\mu \mathrm{mol}$ ATP/mL resin); (B) N6-linked (5 $\mu \mathrm{mol} \mathrm{ATP/mL} \mathrm{resin);} \mathrm{(C)} \mathrm{N8-linked} \mathrm{(5} \mu \mathrm{mol} \mathrm{ATP/mL} \mathrm{resin);} \mathrm{(D)} \mathrm{R-}$ linked (5 $\mu \mathrm{mol} \mathrm{ATP/mL} \mathrm{resin),} \mathrm{and} \mathrm{(E)} \mathrm{cleavable} \mathrm{diazo-P-linked} \mathrm{(0.25} \mu \mathrm{mol} \mathrm{ATP} / \mathrm{mL}$ resin). Following gentle mixing, the unbound fractions containing proteins that were not successfully captured by the ATP Sepharose were collected and probed for NLRP3 by immunoblotting. NLRP3 binding (\%) was calculated from the densitometry data as the [unbound NLRP3 / total NLRP3 input]. Data are representative of three independent experiments using unique whole cell lysates. Bar graphs and error bars represent the mean \pm standard deviation.

FIGURE 3. NLRP3-binding properties with ATP affinity capture chromatography. In (A), plasmids encoding either untagged-NLRP3 or NLRP3-GFP were transfected into HEK293T cells. In (B), PMA-differentiated THP-1 macrophage lysates were combined with P-linked ATPSepharose. After incubation with P-linked ATP-Sepharose, charged beads were washed and developed with ATP solutions. Eluted samples were immunoblotted with anti-NLRP3 antibody. 
FIGURE 4. Ligand density influences NLRP3 capture and competitive elution profiles from

P-linked ATP Sepharose. Whole cell lysates obtained from stably-expressing NLRP3-GFP HEK293T cells were incubated at a 2:1 volumetric ratio with various P-linked ATP Sepharose resins (increasing ligand densities of $0.1-0.25 \mu \mathrm{mol} \mathrm{ATP} / \mathrm{mL}$ ) with gentle mixing for 1 hour at 4 ${ }^{\circ}$ C. (A) The $\%$ capture efficiency was calculated from NLRP3 immunoblot data as the Input Density - [Unbound Density/Input Density]. CL: cell lysate; FT: flow-through, unbound material. (B) Following binding and extensive washing, NLRP3-GFP bound ATP Sepharose resin was evenly distributed to wells of a 96-well filter plates. ATP was added, plates were centrifuged, and the recovered eluents were probed for NLRP3 by immunoblotting. $(\mathbf{C})$, the $\%$ of total eluted NLRP3 by ATP at each of the individual concentrations was calculated. (D), densitometric data also highlight differences in elution profiles observed for each ATP concentration. Data are representative of three independent experiments. Graphs and error bars represent the mean \pm standard deviation.

FIGURE 5. Sample processing with immobilized ATP improves SRM-MS analyses of NLRP3. PMA-differentiated THP-1 cells were treated with nigericin ( $20 \mu \mathrm{M} ; 45 \mathrm{~min})$. Whole cell lysates were used to profile signature peptides originating from NLRP3 protein. Four representative spectra of transitions identified from NLRP3 signature peptides are provided as examples of improved signal detection with P-linked ATP Sepharose sample processing prior to SRM-MS analyses. The peptides and their position within the NLRP3 sequence are indicated above the spectra. Each peptide was identified by its five highest transitions (y- and b-ions), and the arrow head notes the peak of NLRP3 peptide elution. 
FIGURE 6. NLRP proteins are effectively captured with P-linked ATP Sepharose. In (A), HEK293T cells were transfected with various NLRPs-GFP plasmids. Whole cell extracts were incubated with P-linked ATP Sepharose. After incubation, the ATP Sepharose was washed extensively, and the various NLRP-GFPs were eluted with the indicated ATP solutions (0 - 300 $\mathrm{mM}$ ). Fluorescence counts from elution samples were determined using a plate reader (Molecular Devices SpectraMax M2, excitation filter 485nm, emission filter 535nm). In (B), the binding efficiency for each NLRP-GFP is expressed as the (Input Fluorescence - Unbound Fluorescence/Input Fluorescence). In (C), the eluates were further probed for GFP-tagged NLRPs by immunoblotting with anti-GFP antibody. Data are representative of three independent experiments. Bar graphs shown represent the mean \pm standard deviation (error bars).

\section{FIGURE 7. FLECS screening to identify compounds that compete NLRP3 from P-linked}

ATP Sepharose. In (A),HEK293T cell lysates containing NLRP3-GFP were incubated with Plinked ATP Sepharose. After distributing charged beads into 96-well filter plates, drug candidates or ATP solutions (10-250 mM as positive controls) were applied for competitive elution. Displaced proteins were collected by centrifugation in catch plates, and the fluorescence in each well was determined. All wells containing $>3000$ fluorescence counts were considered potential positive hits. Eluate from each NLRP3-GFP positive well was validated by immunblotting. In (B-D), PMAdifferentiated THP-1 cells were primed with LPS $(1 \mathrm{ng} / \mathrm{mL})$ and then treated with extracellular ATP (exATP; $5 \mathrm{mM}, 3 \mathrm{~h})$ in the absence or presence of the indicated drug candidates $(50 \mu \mathrm{M}, 2$ h), and DMSO was used as a vehicle control. After treatment, the culture supernatants were analyzed for IL-1 $\beta$ by ELISA (B). In subsequent studies, HS203873 (indicated concentrations), glyburide $(50 \mu \mathrm{M})$ and Bay 11-7082 $(20 \mu \mathrm{M})$ were applied to THP-1 cells. After exposure to 
extracellular ATP, the cell supernatants were probed for IL-1 $\beta$ by ELISA (C) and processed caspase-1 by immunoblotting (D). Chemical structure of HS203873 is provided in (E). Data are representative of $n=3$ independent experiments. Bar graphs shown represent the mean \pm standard deviation (error bars) of triplicate wells.

\section{FIGURE 8. HS203873 attenuates the ATP-binding, ATP hydrolysis and oligomerization}

properties of NLRP3. In (A), NLRP3 oligomerization can be generated spontaneously in HEK293T cells with co-incident overexpression of FLAG-NLRP3 and NLRP3-GFP. Immunoprecipitation of NLRP3 inflammasomes from lysates with anti-FLAG reveal heteromultimeric NLRP-GFP:FLAG-NLRP complexes. In (B), HS203873 attenuates NLRP3 oligomerization in a concentration-dependent manner. HEK293T cells were transfected as in (A) and incubated with HS203873 for 48 h. Results $(n=3)$ are presented as the $\%$ change (relative to vehicle control) in NLRP3-GFP/FLAG-NLRP signal ratio as measured by densitometry following immunoprecipitation and western blotting. *-significantly different from vehicle control by ANOVA analysis with Dunnett's post hoc test. In (C), in vitro ATPase assays were completed with immunoprecipitated NLRP3-GFP in the absence and presence of HS203873 (100 $\mu \mathrm{M})$. Results are presented as the \% change in the nmoles of ADP produced relative to the vehicle control. Bar graphs represent the mean \pm standard deviation ( $\mathrm{n}=5$ independent assays). *significantly different from vehicle control; $\mathbf{p}<0.05$, Student's t-test. In (D), HEK293T cells were transfected with NLRP3-GFP plasmid. Whole cell lysates were incubated with P-linked ATP Sepharose, and then charged beads were developed with HS203873 (0-1 mM) or ATP (200 mM). The elutions were probed for GFP-tagged NLRP3 by immunoblotting. In (E), whole cell HEK293T lysates containing expressed NLRP3-GFP were pre-exposed to HS203873 (0 - $1 \mathrm{mM})$ 
or $200 \mathrm{mM}$ ATP prior to incubation with P-linked ATP Sepharose. NLRP3-GFP was measured in the unbound fraction. Data in $(\mathbf{D})$ and $(\mathbf{E})$ are representative of two independent replicates. 


\section{References}

1. Latz, E., T.S. Xiao, and A. Stutz, Activation and regulation of the inflammasomes. Nat Rev Immunol, 2013. 13(6): p. 397-411.

2. Sharma, D. and T.D. Kanneganti, The cell biology of inflammasomes: Mechanisms of inflammasome activation and regulation. J Cell Biol, 2016. 213(6): p. 617-29.

3. Mathur, A., J.A. Hayward, and S.M. Man, Molecular mechanisms of inflammasome signaling. J Leukoc Biol, 2018. 103(2): p. 233-257.

4. Hayward, J.A., et al., Cytosolic Recognition of Microbes and Pathogens: Inflammasomes in Action. Microbiol Mol Biol Rev, 2018. 82(4).

5. $\mathrm{Yu}, \mathrm{H} . \mathrm{B}$. and B.B. Finlay, The caspase-1 inflammasome: a pilot of innate immune responses. Cell Host Microbe, 2008. 4(3): p. 198-208.

6. Kayagaki, N., et al., Non-canonical inflammasome activation targets caspase-11. Nature, 2011. 479(7371): p. 117-21.

7. Man, S.M., et al., Salmonella infection induces recruitment of Caspase-8 to the inflammasome to modulate IL-1beta production. J Immunol, 2013. 191(10): p. 5239-46.

8. Dinarello, C.A., Overview of the IL-1 family in innate inflammation and acquired immunity. Immunol Rev, 2018. 281(1): p. 8-27.

9. $\quad$ Ting, J.P., et al., The NLR gene family: a standard nomenclature. Immunity, 2008. 28(3): p. $285-7$.

10. Lechtenberg, B.C., P.D. Mace, and S.J. Riedl, Structural mechanisms in NLR inflammasome signaling. Curr Opin Struct Biol, 2014. 29: p. 17-25.

11. Manji, G.A., et al., PYPAF1, a PYRIN-containing Apafl-like protein that assembles with ASC and regulates activation of NF-kappa B. J Biol Chem, 2002. 277(13): p. 11570-5.

12. Srinivasula, S.M., et al., The PYRIN-CARD protein ASC is an activating adaptor for caspase-1. J Biol Chem, 2002. 277(24): p. 21119-22.

13. Duncan, J.A., et al., Cryopyrin/NALP3 binds ATP/dATP, is an ATPase, and requires ATP binding to mediate inflammatory signaling. Proc Natl Acad Sci U S A, 2007. 104(19): p. 8041-6.

14. Mariathasan, S., et al., Cryopyrin activates the inflammasome in response to toxins and ATP. Nature, 2006. 440(7081): p. 228-32.

15. Dostert, C., et al., Innate immune activation through Nalp3 inflammasome sensing of asbestos and silica. Science, 2008. 320(5876): p. 674-7.

16. Hornung, V., et al., Silica crystals and aluminum salts activate the NALP3 inflammasome through phagosomal destabilization. Nat Immunol, 2008. 9(8): p. 847-56.

17. Halle, A., et al., The NALP3 inflammasome is involved in the innate immune response to amyloid-beta. Nat Immunol, 2008. 9(8): p. 857-65.

18. Duewell, P., et al., NLRP3 inflammasomes are required for atherogenesis and activated by cholesterol crystals. Nature, 2010. 464(7293): p. 1357-61.

19. Pan, J., et al., Fatty acid activates NLRP3 inflammasomes in mouse Kupffer cells through mitochondrial DNA release. Cell Immunol, 2018. 332: p. 111-120.

20. Martinon, F., et al., Gout-associated uric acid crystals activate the NALP3 inflammasome. Nature, 2006. 440(7081): p. 237-41.

21. Wang, X., et al., Structure Activity Relationships of Engineered Nanomaterials in inducing NLRP3 Inflammasome Activation and Chronic Lung Fibrosis. NanoImpact, 2017. 6: p. 99108. 
22. Ferko, M.A. and I. Catelas, Effects of metal ions on caspase-1 activation and interleukinIbeta release in murine bone marrow-derived macrophages. PLoS One, 2018. 13(8): p. e0199936.

23. Cruz, C.M., et al., ATP activates a reactive oxygen species-dependent oxidative stress response and secretion of proinflammatory cytokines in macrophages. J Biol Chem, 2007. 282(5): p. 2871-9.

24. Lee, G.S., et al., The calcium-sensing receptor regulates the NLRP3 inflammasome through Ca2+ and cAMP. Nature, 2012. 492(7427): p. 123-7.

25. Munoz-Planillo, R., et al., $K(+)$ efflux is the common trigger of NLRP3 inflammasome activation by bacterial toxins and particulate matter. Immunity, 2013. 38(6): p. 1142-53.

26. Petrilli, V., et al., Activation of the NALP3 inflammasome is triggered by low intracellular potassium concentration. Cell Death Differ, 2007. 14(9): p. 1583-9.

27. Park, S., et al., The mitochondrial antiviral protein MAVS associates with NLRP3 and regulates its inflammasome activity. J Immunol, 2013. 191(8): p. 4358-66.

28. Subramanian, N., et al., The adaptor MAVS promotes NLRP3 mitochondrial localization and inflammasome activation. Cell, 2013. 153(2): p. 348-61.

29. Zhou, R., et al., A role for mitochondria in NLRP3 inflammasome activation. Nature, 2011. 469(7329): p. 221-5.

30. Hoyt, L.R., et al., Mitochondrial ROS induced by chronic ethanol exposure promote hyperactivation of the NLRP3 inflammasome. Redox Biol, 2017. 12: p. 883-896.

31. Elliott, E.I., et al., Cutting Edge: Mitochondrial Assembly of the NLRP3 Inflammasome Complex Is Initiated at Priming. J Immunol, 2018. 200(9): p. 3047-3052.

32. Guo, C., et al., Bile Acids Control Inflammation and Metabolic Disorder through Inhibition of NLRP3 Inflammasome. Immunity, 2016. 45(4): p. 802-816.

33. Mortimer, L., et al., NLRP3 inflammasome inhibition is disrupted in a group of autoinflammatory disease CAPS mutations. Nat Immunol, 2016. 17(10): p. 1176-86.

34. Stutz, A., et al., NLRP3 inflammasome assembly is regulated by phosphorylation of the pyrin domain. J Exp Med, 2017. 214(6): p. 1725-1736.

35. Juliana, C., et al., Non-transcriptional priming and deubiquitination regulate NLRP3 inflammasome activation. J Biol Chem, 2012. 287(43): p. 36617-22.

36. Py, B.F., et al., Deubiquitination of NLRP3 by BRCC3 critically regulates inflammasome activity. Mol Cell, 2013. 49(2): p. 331-8.

37. Kattah, M.G., B.A. Malynn, and A. Ma, Ubiquitin-Modifying Enzymes and Regulation of the Inflammasome. J Mol Biol, 2017. 429(22): p. 3471-3485.

38. Koonin, E.V. and L. Aravind, The NACHT family - a new group of predicted NTPases implicated in apoptosis and MHC transcription activation. Trends Biochem Sci, 2000. 25(5): p. 223-4.

39. Leipe, D.D., E.V. Koonin, and L. Aravind, STAND, a class of P-loop NTPases including animal and plant regulators of programmed cell death: multiple, complex domain architectures, unusual phyletic patterns, and evolution by horizontal gene transfer. J Mol Biol, 2004. 343(1): p. 1-28.

40. Hughes, A.L., Evolutionary relationships of vertebrate NACHT domain-containing proteins. Immunogenetics, 2006. 58(10): p. 785-91.

41. Danot, O., et al., Wheel of Life, Wheel of Death: A Mechanistic Insight into Signaling by STAND Proteins. Structure, 2009. 17(2): p. 172-82. 
42. Riedl, S.J., et al., Structure of the apoptotic protease-activating factor 1 bound to ADP. Nature, 2005. 434(7035): p. 926-33.

43. Proell, M., et al., The Nod-like receptor (NLR) family: a tale of similarities and differences. PLoS One, 2008. 3(4): p. e2119.

44. MacDonald, J.A., et al., Biochemical and structural aspects of the ATP-binding domain in inflammasome-forming human NLRP proteins. IUBMB Life, 2013. 65(10): p. 851-62.

45. Radian, A.D., et al., ATP binding by NLRP7 is required for inflammasome activation in response to bacterial lipopeptides. Mol Immunol, 2015. 67(2 Pt B): p. 294-302.

46. Ye, Z., et al., ATP binding by monarch-1/NLRP12 is critical for its inhibitory function. Mol Cell Biol, 2008. 28(5): p. 1841-50.

47. Faustin, B., et al., Reconstituted NALP1 inflammasome reveals two-step mechanism of caspase-1 activation. Mol Cell, 2007. 25(5): p. 713-24.

48. Martino, L., et al., The Biophysical Characterisation and SAXS Analysis of Human NLRP1 Uncover a New Level of Complexity of NLR Proteins. PLoS One, 2016. 11(10): p. e0164662.

49. Grez, M. and J. Niessing, Affinity chromatography of poly(A) polymerase on ATPSepharose. FEBS Lett, 1977. 77(1): p. 57-60.

50. Haystead, C.M., et al., Gamma-phosphate-linked ATP-sepharose for the affinity purification of protein kinases. Rapid purification to homogeneity of skeletal muscle mitogen-activated protein kinase kinase. Eur J Biochem, 1993. 214(2): p. 459-67.

51. MacDonald, J.A. and K.B. Storey, Temperature and phosphate effects on allosteric phenomena of phosphofructokinase from a hibernating ground squirrel (Spermophilus lateralis). FEBS J, 2005. 272(1): p. 120-8.

52. Moudgil, V.K. and T.E. Eessalu, Inhibition of nuclear uptake and ATP-Sepharose binding of progesterone-receptor complex by aurintricarboxylic acid. Arch Biochem Biophys, 1982. 213(1): p. 98-108.

53. T'Jampens, D., et al., Selected BTB/POZ-kelch proteins bind ATP. FEBS Lett, 2002. 516(13): p. 20-6.

54. Kikuchi, N., et al., Molecular shape and ATP binding activity of rat p50, a putative mammalian homologue of RuvB DNA helicase. J Biochem, 1999. 125(3): p. 487-94.

55. Kim, S.Y., et al., Rapid purification and characterization of nucleoside diphosphate kinase isoforms using ATP-sepharose affinity column chromatography. Mol Cells, 1997. 7(5): p. 630-4.

56. Duncan, J.S., T.A. Haystead, and D.W. Litchfield, Chemoproteomic characterization of protein kinase inhibitors using immobilized ATP. Methods Mol Biol, 2012. 795: p. 11934.

57. $\mathrm{Hu}, \mathrm{Z}$., et al., Crystal structure of NLRC4 reveals its autoinhibition mechanism. Science, 2013. 341(6142): p. 172-5.

58. Trayer, I.P. and H.R. Trayer, Affinity chromatography of nicotinamide nucleotidedependent dehydrogenases on immobilized nucleotide derivatives. Biochem J, 1974. 141(3): p. 775-87.

59. Boja, E.S. and H. Rodriguez, Mass spectrometry-based targeted quantitative proteomics: achieving sensitive and reproducible detection of proteins. Proteomics, 2012. 12(8): p. 1093-110.

60. Ebhardt, H.A., et al., Applications of targeted proteomics in systems biology and translational medicine. Proteomics, 2015. 15(18): p. 3193-208. 
61. Gillette, M.A. and S.A. Carr, Quantitative analysis of peptides and proteins in biomedicine by targeted mass spectrometry. Nat Methods, 2013. 10(1): p. 28-34.

62. Craig, R., et al., Using annotated peptide mass spectrum libraries for protein identification. J Proteome Res, 2006. 5(8): p. 1843-9.

63. Uhlen, M., et al., Proteomics. Tissue-based map of the human proteome. Science, 2015. 347(6220): p. 1260419.

64. Craig, R., J.P. Cortens, and R.C. Beavis, The use of proteotypic peptide libraries for protein identification. Rapid Commun Mass Spectrom, 2005. 19(13): p. 1844-50.

65. Pino, L.K., et al., The Skyline ecosystem: Informatics for quantitative mass spectrometry proteomics. Mass Spectrom Rev, 2017.

66. Rost, H., L. Malmstrom, and R. Aebersold, A computational tool to detect and avoid redundancy in selected reaction monitoring. Mol Cell Proteomics, 2012. 11(8): p. 540-9.

67. Craig, R., J.P. Cortens, and R.C. Beavis, Open source system for analyzing, validating, and storing protein identification data. J Proteome Res, 2004. 3(6): p. 1234-42.

68. Liu, X., et al., Mapping the human plasma proteome by SCX-LC-IMS-MS. J Am Soc Mass Spectrom, 2007. 18(7): p. 1249-64.

69. Carlson, D.A., et al., Fluorescence linked enzyme chemoproteomic strategy for discovery of a potent and selective DAPK1 and ZIPK inhibitor. ACS Chem Biol, 2013. 8(12): p. 2715-23.

70. Fadden, P., et al., Application of chemoproteomics to drug discovery: identification of a clinical candidate targeting hsp90. Chem Biol, 2010. 17(7): p. 686-94.

71. Graves, P.R., et al., Discovery of novel targets of quinoline drugs in the human purine binding proteome. Mol Pharmacol, 2002. 62(6): p. 1364-72.

72. Howe, M.K., et al., Identification of an allosteric small-molecule inhibitor selective for the inducible form of heat shock protein 70. Chem Biol, 2014. 21(12): p. 1648-59.

73. Kulkarni, M.M., et al., Cellular fatty acid synthase is required for late stages of HIV-1 replication. Retrovirology, 2017. 14(1): p. 45.

74. Haystead, T.A., The purinome, a complex mix of drug and toxicity targets. Curr Top Med Chem, 2006. 6(11): p. 1117-27.

75. Zhang, J.H., T.D. Chung, and K.R. Oldenburg, A Simple Statistical Parameter for Use in Evaluation and Validation of High Throughput Screening Assays. J Biomol Screen, 1999. 4(2): p. 67-73.

76. Guo, H., J.B. Callaway, and J.P. Ting, Inflammasomes: mechanism of action, role in disease, and therapeutics. Nat Med, 2015. 21(7): p. 677-87.

77. Martinon, F., K. Burns, and J. Tschopp, The inflammasome: a molecular platform triggering activation of inflammatory caspases and processing of proIL-beta. Mol Cell, 2002. 10(2): p. 417-26.

78. Perregaux, D.G., et al., Identification and characterization of a novel class of interleukin1 post-translational processing inhibitors. J Pharmacol Exp Ther, 2001. 299(1): p. 187-97.

79. Laliberte, R.E., et al., Glutathione s-transferase omega 1-1 is a target of cytokine release inhibitory drugs and may be responsible for their effect on interleukin-1beta posttranslational processing. J Biol Chem, 2003. 278(19): p. 16567-78.

80. Coll, R.C., et al., The cytokine release inhibitory drug CRID3 targets ASC oligomerisation in the NLRP3 and AIM2 inflammasomes. PLoS One, 2011. 6(12): p. e29539.

81. Coll, R.C., et al., A small-molecule inhibitor of the NLRP3 inflammasome for the treatment of inflammatory diseases. Nat Med, 2015. 21(3): p. 248-55. 
82. Fan, S.H., et al., Luteoloside suppresses proliferation and metastasis of hepatocellular carcinoma cells by inhibition of NLRP3 inflammasome. PLoS One, 2014. 9(2): p. e89961.

83. Guo, W., et al., Small molecule-driven mitophagy-mediated NLRP3 inflammasome inhibition is responsible for the prevention of colitis-associated cancer. Autophagy, 2014. 10(6): p. 972-85.

84. Gong, Y.N., et al., Chemical probing reveals insights into the signaling mechanism of inflammasome activation. Cell Res, 2010. 20(12): p. 1289-305.

85. Lamkanfi, M., et al., Glyburide inhibits the Cryopyrin/Nalp3 inflammasome. J Cell Biol, 2009. 187(1): p. 61-70.

86. Marchetti, C., et al., A novel pharmacologic inhibitor of the NLRP3 inflammasome limits myocardial injury after ischemia-reperfusion in the mouse. J Cardiovasc Pharmacol, 2014. 63(4): p. 316-22.

87. Liu, W., et al., A novel benzo[d]imidazole derivate prevents the development of dextran sulfate sodium-induced murine experimental colitis via inhibition of NLRP3 inflammasome. Biochem Pharmacol, 2013. 85(10): p. 1504-12.

88. Juliana, C., et al., Anti-inflammatory compounds parthenolide and Bay 11-7082 are direct inhibitors of the inflammasome. J Biol Chem, 2010. 285(13): p. 9792-802.

89. Rodgers, M.A., et al., The linear ubiquitin assembly complex (LUBAC) is essential for NLRP3 inflammasome activation. J Exp Med, 2014. 211(7): p. 1333-47.

90. Strickson, S., et al., The anti-inflammatory drug BAY 11-7082 suppresses the MyD88dependent signalling network by targeting the ubiquitin system. Biochem J, 2013. 451(3): p. 427-37.

91. He, Y., et al., 3,4-methylenedioxy-beta-nitrostyrene inhibits NLRP3 inflammasome activation by blocking assembly of the inflammasome. J Biol Chem, 2014. 289(2): p. 114250 .

92. Cocco, M., et al., Electrophilic warhead-based design of compounds preventing NLRP3 inflammasome-dependent pyroptosis. J Med Chem, 2014. 57(24): p. 10366-82.

93. Cocco, M., et al., Design, Synthesis, and Evaluation of Acrylamide Derivatives as Direct NLRP3 Inflammasome Inhibitors. ChemMedChem, 2016. 11(16): p. 1790-803.

94. Cocco, M., et al., Development of an Acrylate Derivative Targeting the NLRP3 Inflammasome for the Treatment of Inflammatory Bowel Disease. J Med Chem, 2017. 60(9): p. 3656-3671.

95. Jiang, H., et al., Identification of a selective and direct NLRP3 inhibitor to treat inflammatory disorders. J Exp Med, 2017. 214(11): p. 3219-3238.

96. Honda, H., et al., Isoliquiritigenin is a potent inhibitor of NLRP3 inflammasome activation and diet-induced adipose tissue inflammation. J Leukoc Biol, 2014. 96(6): p. 1087-100.

97. Maier, N.K., S.H. Leppla, and M. Moayeri, The cyclopentenone prostaglandin 15d-PGJ2 inhibits the NLRP1 and NLRP3 inflammasomes. J Immunol, 2015. 194(6): p. 2776-85.

98. Hughes, P.F., J.J. Barrott, D.A. Carlson, D.R. Loiselle, B.L. Speer, K. Bodoor, L.A. Rund, and T.A.J. Haystead, A highly selective Hsp90 affinity chromatography resin with a cleavable linker. Bioorg Med Chem, 2012. 20(10), 3298-305.

99. Haneklaus, M., J.D. O’Neil, A.R. Clark, S.L. Masters, and L.A.J. O'Neill, The RNAbinding protein tristetraprolin (TTP) is a critical negative regulator of the NLRP3 inflammasome. J Biol Chem, 2017. 292(17), 6869-881.

100. Boucher, D., et al., Caspase-1 self-cleavage is an intrinsic mechanism to terminate inflammasome activity. J Exp Med, 2018. 215(3), 827-40. 


LINKAGE


Cell Lysate : Sepharose 1:1 $\quad 1: 2 \quad 1: 4 \quad 2: 1 \quad$ Input

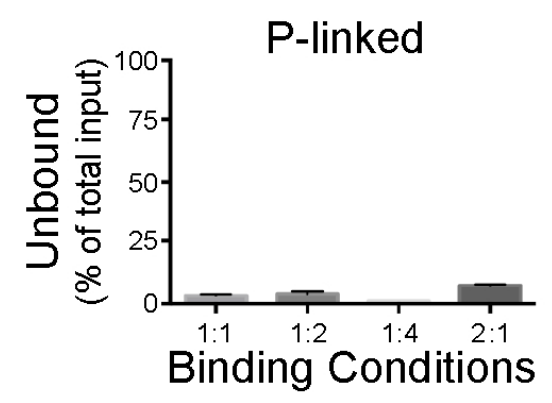

Cell Lysate : Sepharose $\begin{array}{lllll}1: 1 & 1: 2 & 1: 4 & 2: 1 & \text { Input }\end{array}$

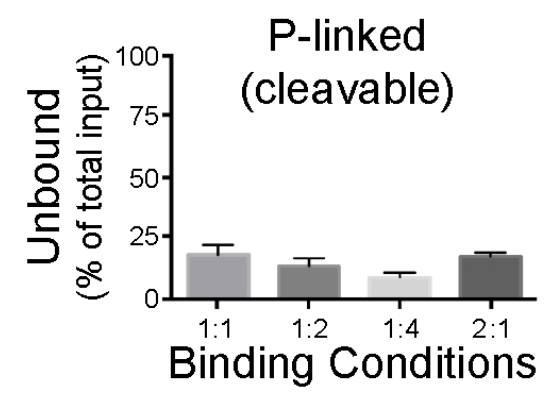

Cell Lysate : Sepharose 1:1 $\quad 1: 2 \quad 1: 4 \quad 2: 1 \quad$ Input

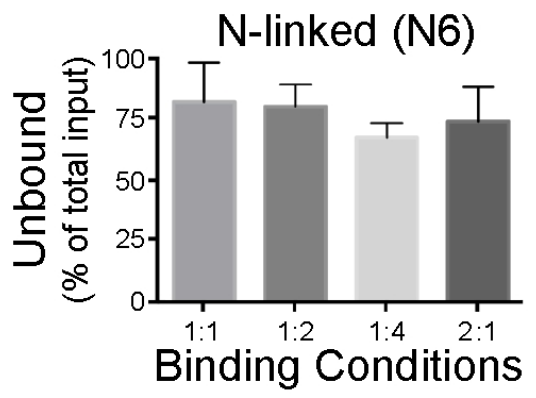

Cell Lysate : Sepharose 1:1 $\quad 1: 2 \quad 1: 4 \quad 2: 1 \quad$ Input

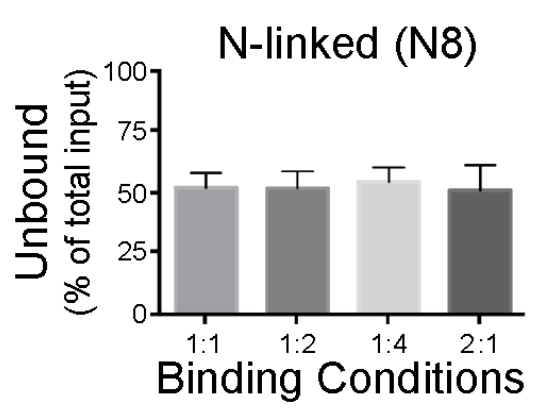

Cell Lysate : Sepharose 1:1 $\quad 1: 2 \quad 1: 4 \quad 2: 1 \quad$ Input

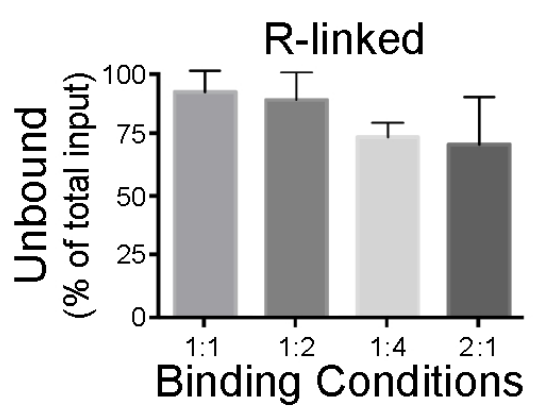




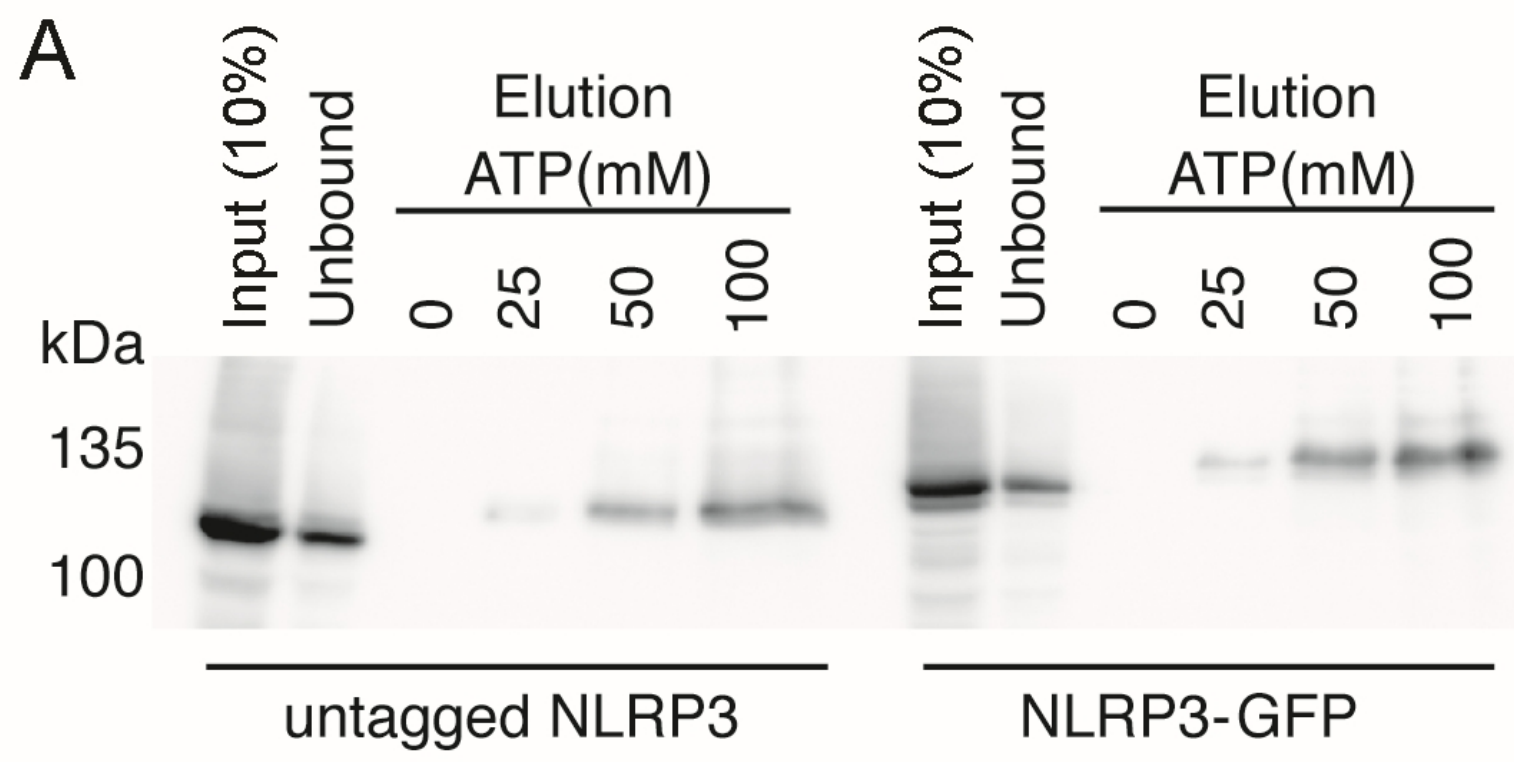

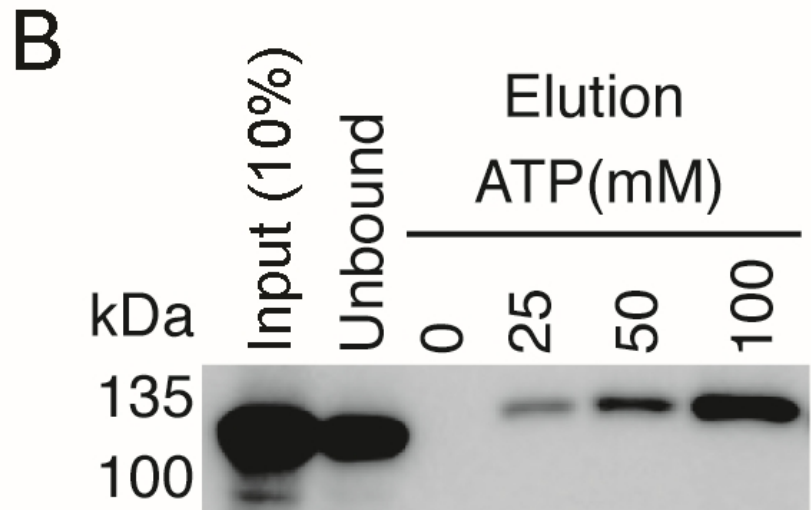



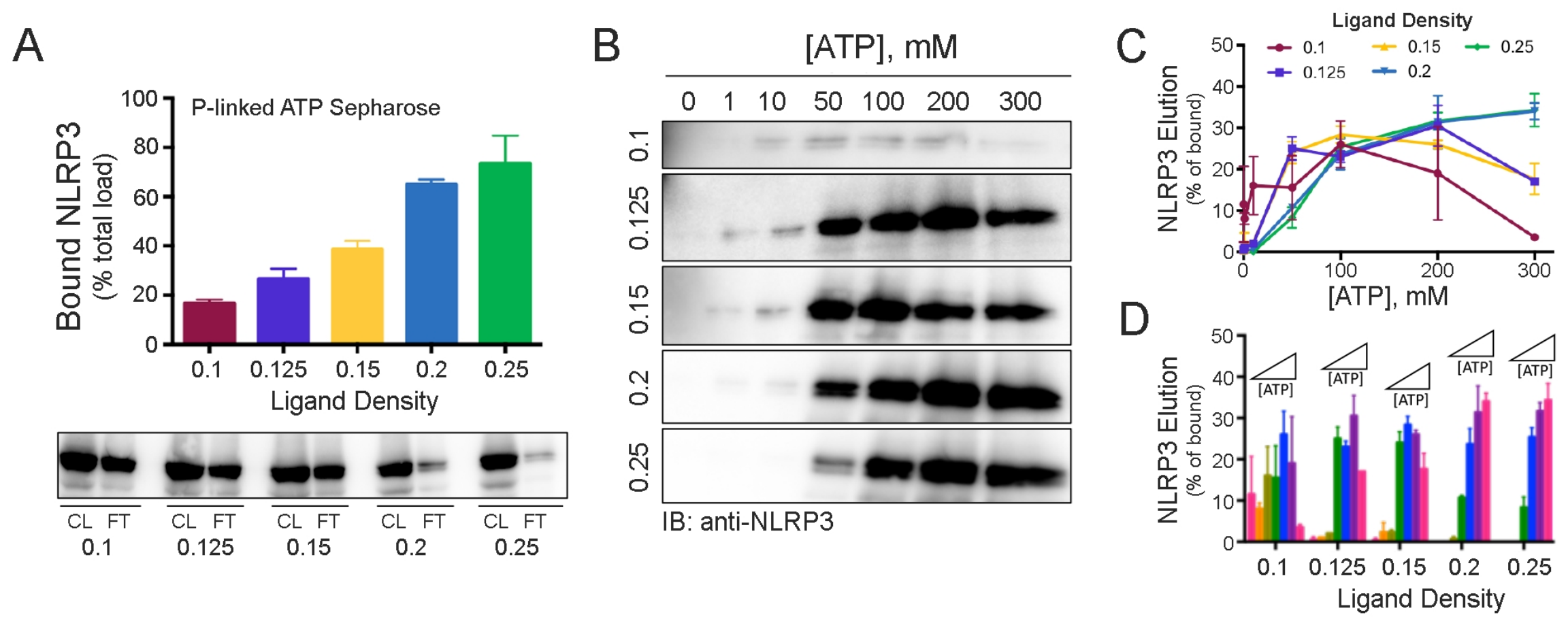

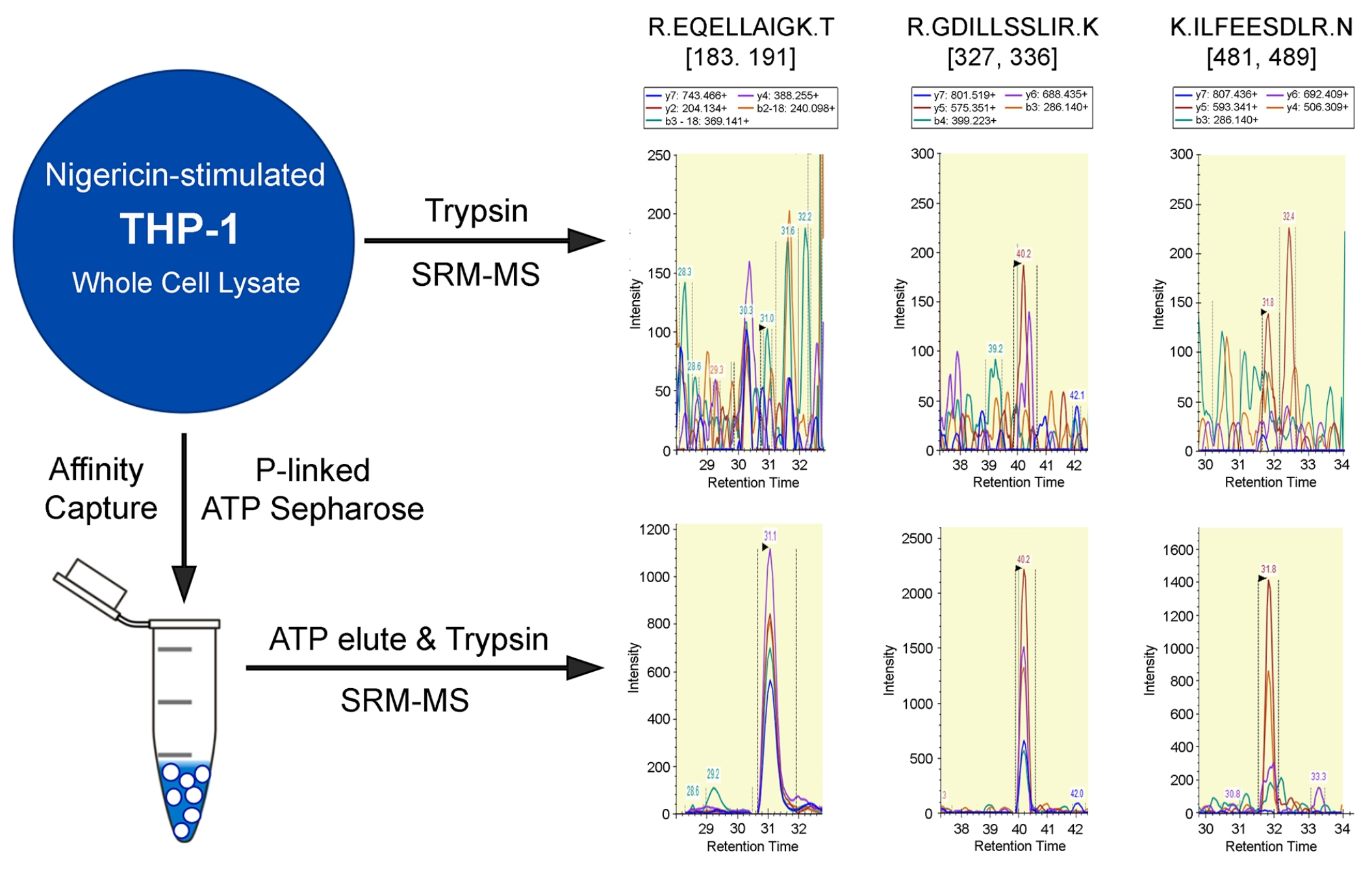

K.ADVSAFLR.M

[496, 503]

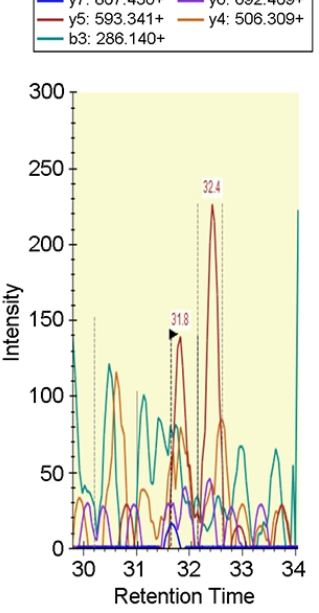

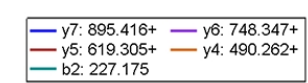

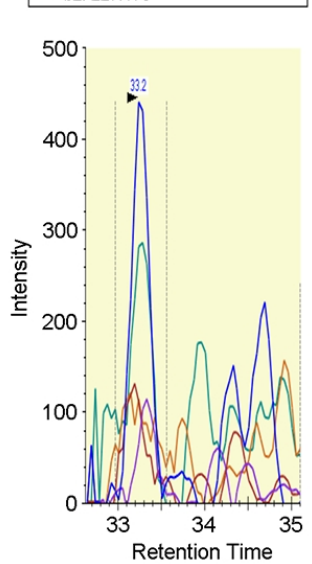

Capture
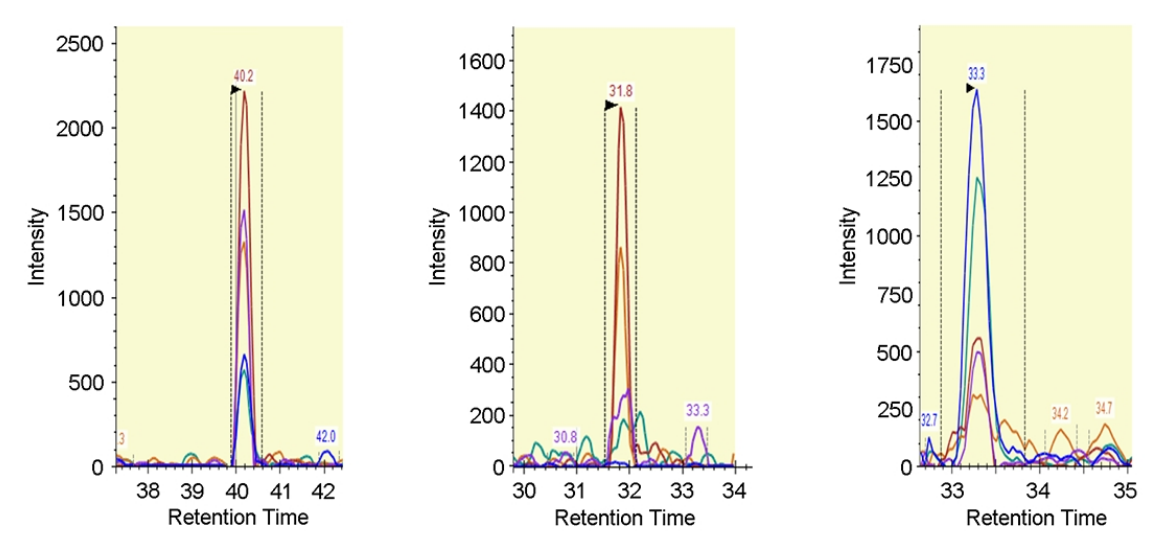
A

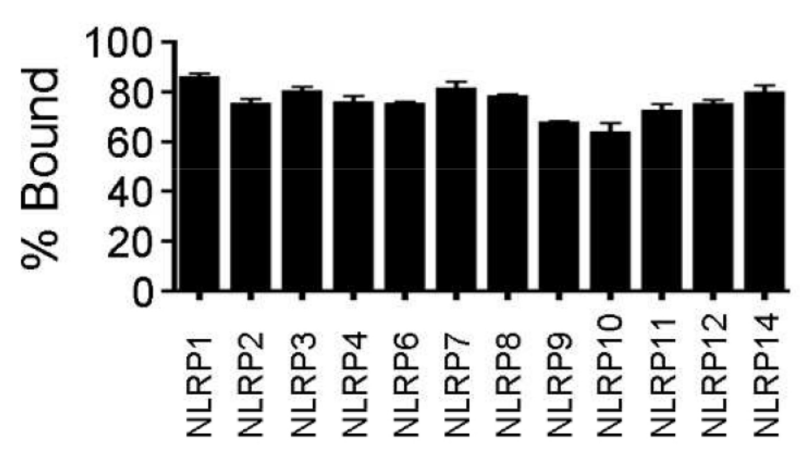

B

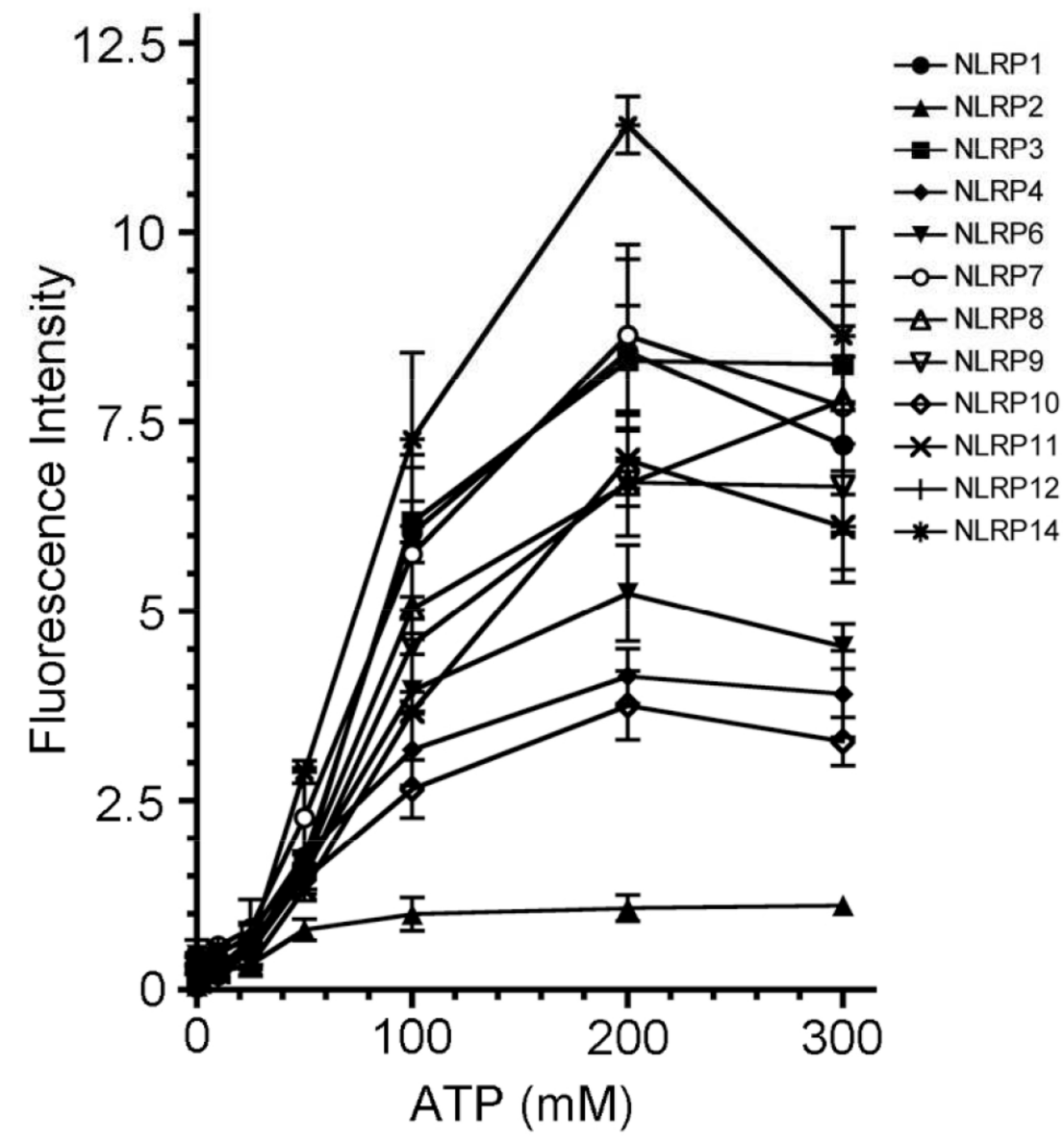

C

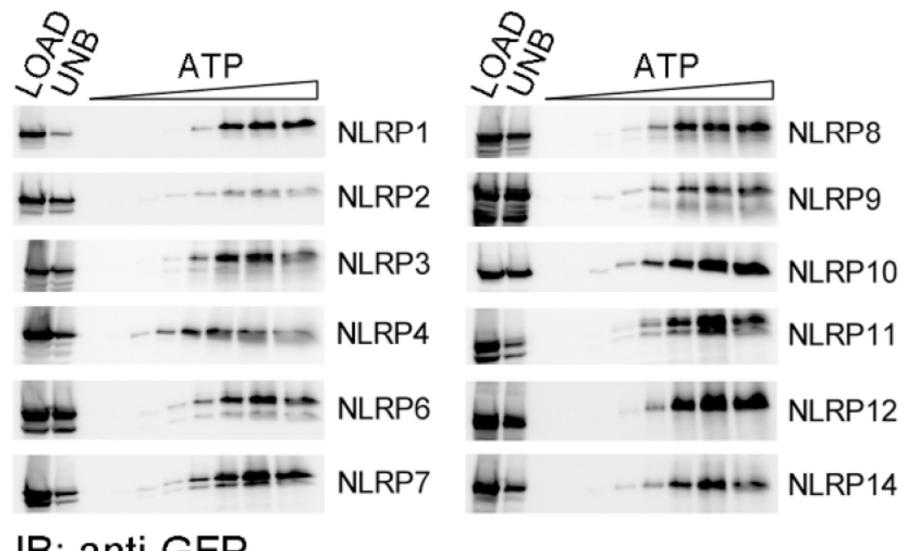

IB: anti-GFP 


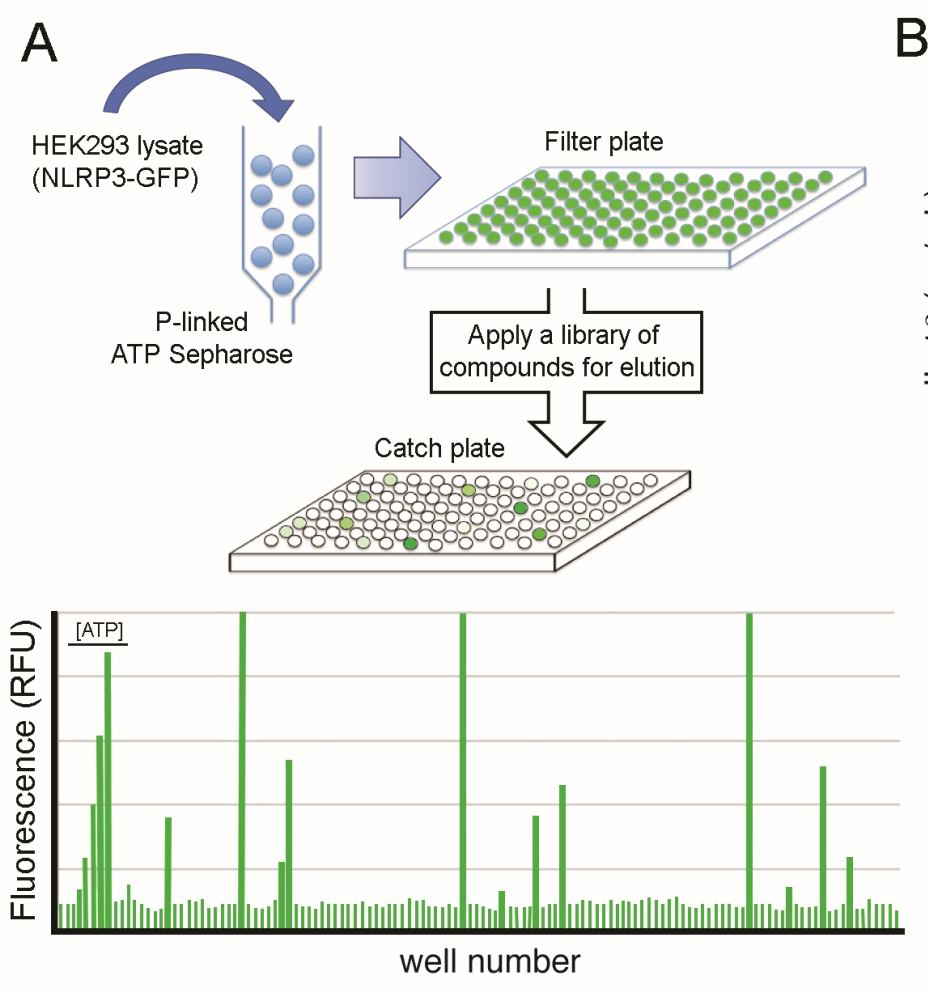

\section{FLECS Screen of NLRP3 Competitors}

Library of Small Molecules ( 3,400 compounds)

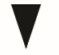

$\sim 120$ positive hits $(3.5 \%)$ by fluorescence

$$
\nabla
$$

9 confirmed hits $(0.26 \%)$ by immunoblotting analysis

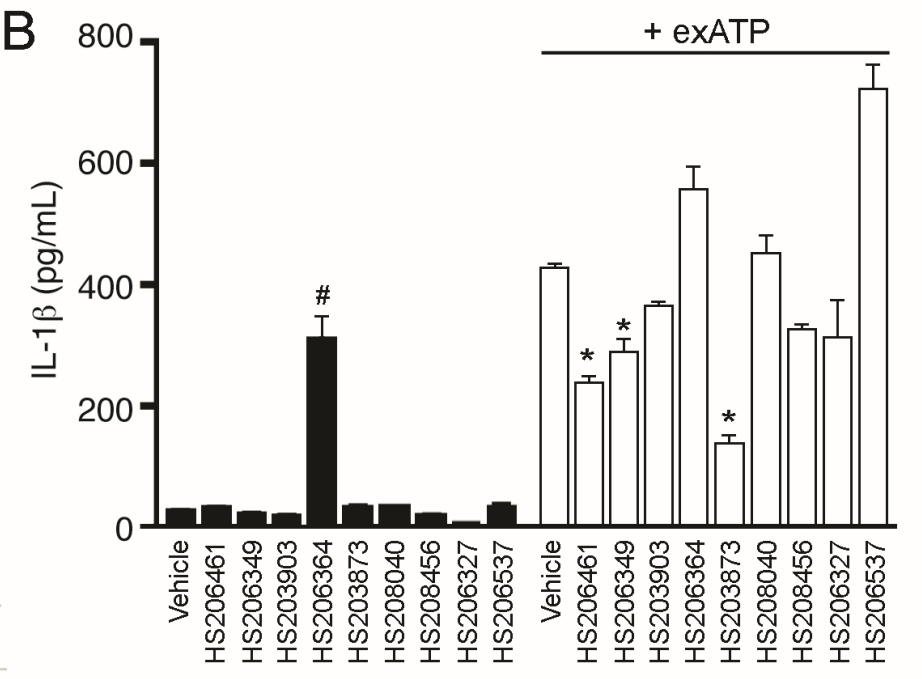

C

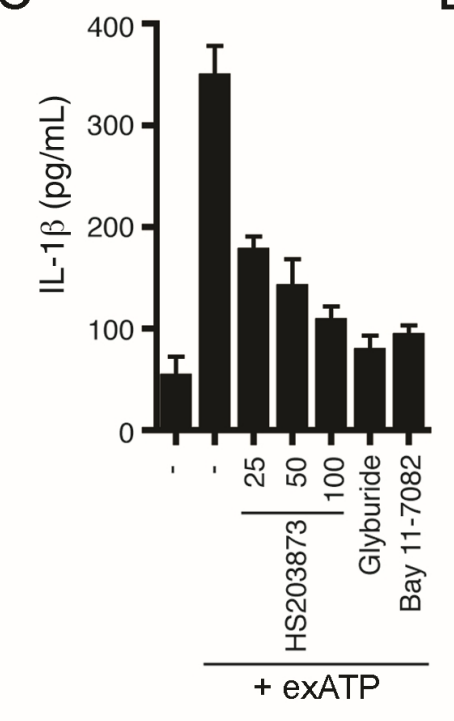

D

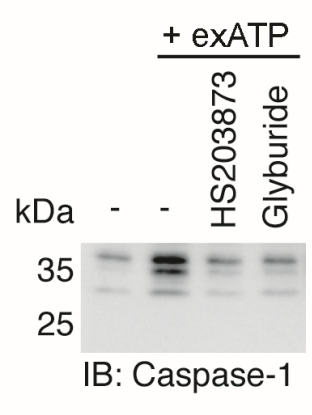

$E$

HS-203873

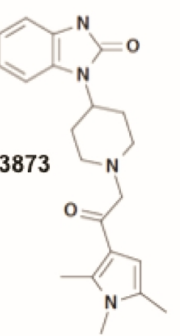


A

B

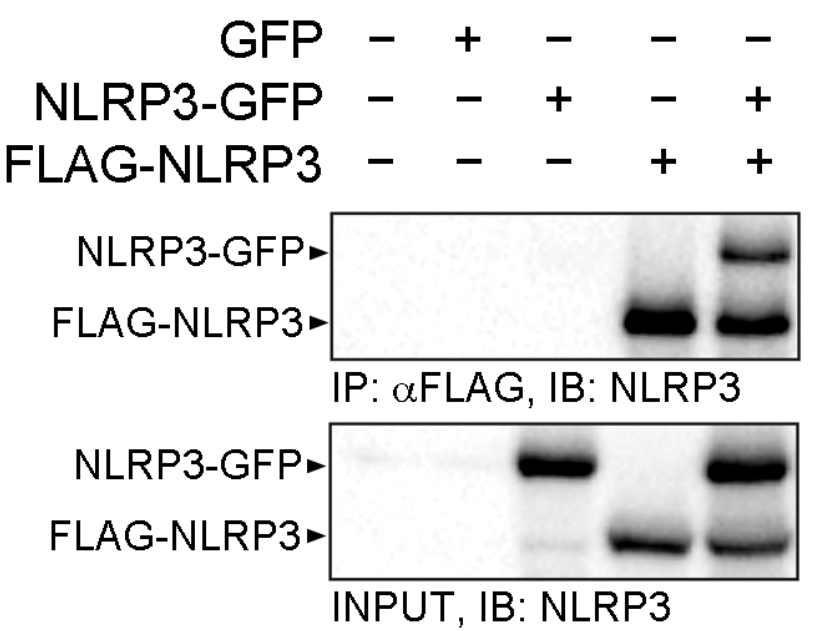

C

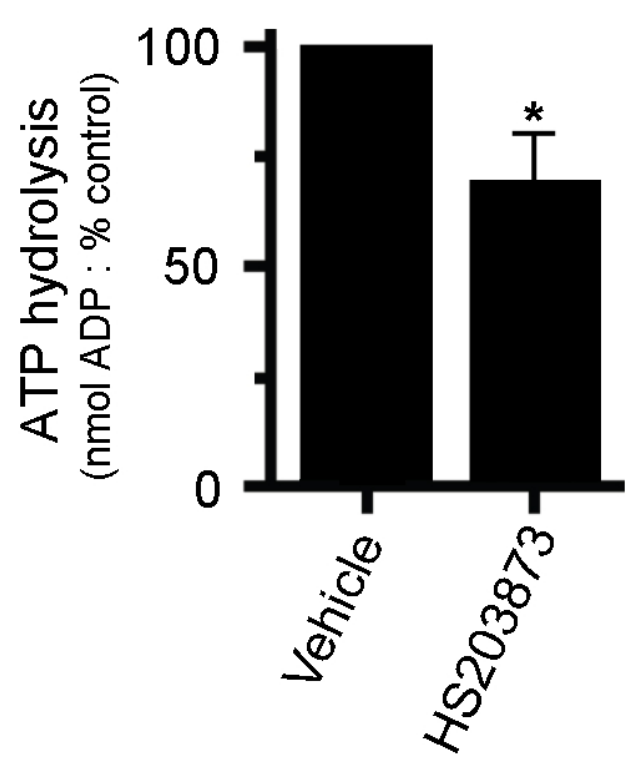

D

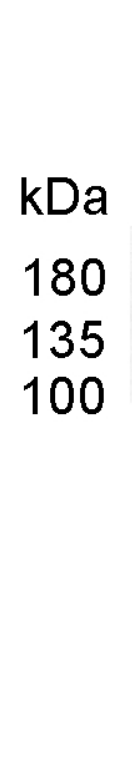

$$
\begin{aligned}
& \text { HS203873 }(\mu \mathrm{M}) \quad 0 \quad 1 \quad 10 \quad 50 \\
& \text { NLRP3-GFP }++++ \\
& \text { FLAG-NLRP3 }++++ \\
& \text { FLAG-NLRP3- } \\
& \text { NLRP3-GFP. } \\
& \text { FLAG-NLRP3- } \\
& \text { INPUT, IB: NLRP3 }
\end{aligned}
$$

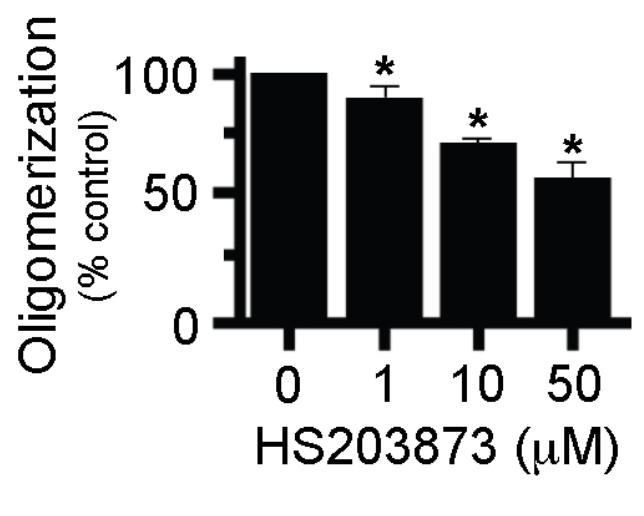

E

HS203873 ( $\mu \mathrm{M})$

罗 0 으응ㅇㅇㅇㅇㅛ 운 온

$\mathrm{kDa}$

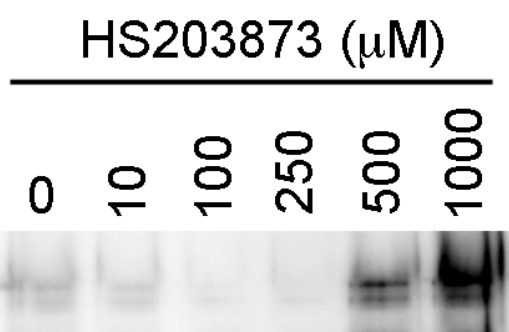

135

unbound fractions IB: NLRP3
Elutions fr. ATP Sepharose

IB: NLRP3 